
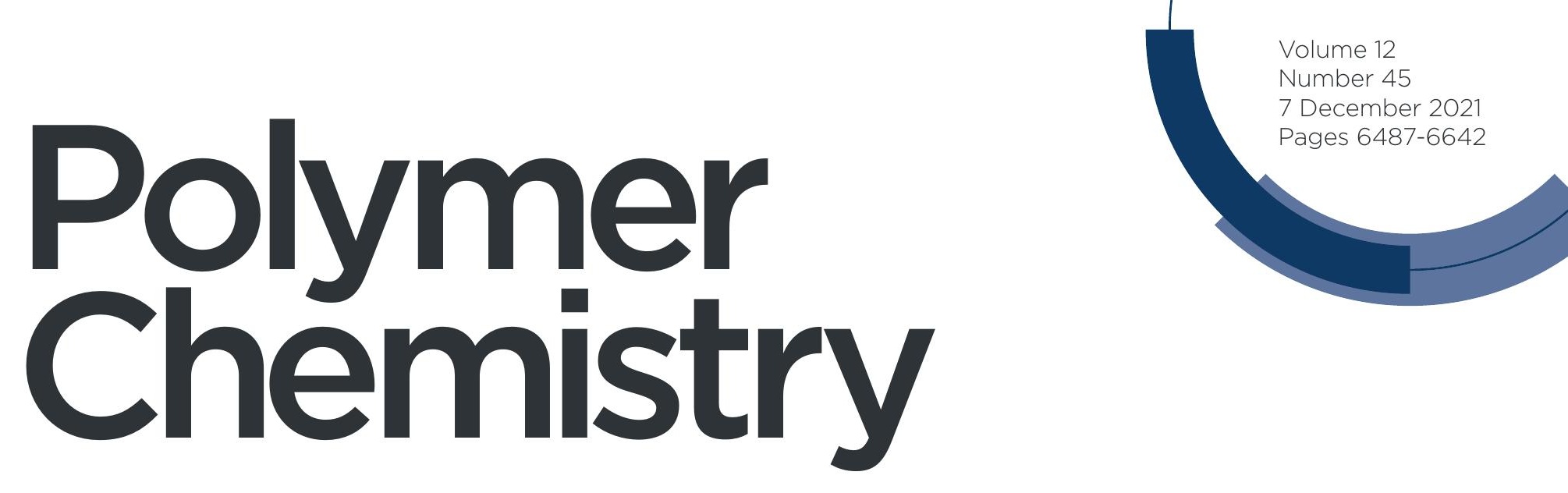

rsc.li/polymers

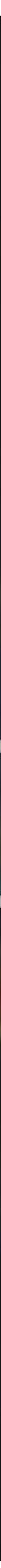

ISSN 1759-9962

ROYAL SOCIETY OF CHEMISTRY

\section{REVIEW ARTICLE}

Charl F. J. Faul et al.

Crosslinked porous polyimides: structure, properties and applications 


\section{A) Check for updates}

Cite this: Polym. Chem., 2021, 12, 6494

Received 23rd July 2021 Accepted 16th September 2021

DOI: 10.1039/d1py00997d

rsc.li/polymers

\title{
Crosslinked porous polyimides: structure, properties and applications
}

\author{
Basiram Brahma Narzary, (DD a Benjamin C. Baker, (D) a Neha Yadav, (DD b Valerio D'Elia (DD b \\ and Charl F. J. Faul (iD) *a
}

Porous polyimides (pPIs) represent a fascinating class of porous organic polymers (POPs). Not only do they exhibit high thermal and chemical stabilities, high surface areas, and energy storage capabilities, but their formation relies upon simple polycondensation reactions. A wide library of linker (dianhydrides) and core (amines) starting materials offers a vast range of crosslinked pPIs. This review details and carefully compares the unique properties and functions of both amorphous and crystalline pPIs. Furthermore, their applications in current global challenges in the fields of gas storage and separation, electrical energy storage, catalysis, drug delivery and sensors are reported. Finally, the review highlights the progress of pPIs since 2010 and offers an outlook and suggestions for future areas for exploration and potential applications within the field.

\section{Introduction}

Polyimide (PI) polymers were first synthesised and reported by Borget et al. in $1908 .^{1}$ PIs can be divided into two classes, aromatic and aliphatic. The first aromatic PI was developed and commercialised by DuPont ${ }^{\mathrm{TM}}$ in 1960 and an aliphatic first reported in 1971 by Hirsch et $a l^{2-4}$ Initially, aromatic PIs were found to exhibit higher thermal, chemical and mechanical stabilities than aliphatic PIs, whereas, aliphatic PIs possess good solubility, low dielectric constant and high optical transparency owing to their molecular packing and polarisability. ${ }^{5}$ PIs have found general use and application in the fields of aviation, aerospace, micro-electronics, gas separation, membranes, fuel cells, batteries, electronic memory devices, shape memory devices, optical devices, biomedical applications, sensors, aerogels and polymer matrices in composites/hybrid materials (Fig. 1). ${ }^{6-12}$

Generally speaking, porous PIs (pPIs) are a class of porous organic polymers (POPs) synthesised by polycondensation reaction between amines and anhydrides (at high temperatures, $180-200^{\circ} \mathrm{C}$ ). Crosslinking is achieved either by multiple $(>2)$ reactive sites or cross-linkable groups (e.g. alkylene) present in the starting materials. pPIs offer high flexibility of their molecular design by variation of the monomer units to yield 3D-crosslinked networks. Moreover, pPIs can also be classified according to their initial building blocks: conju-

${ }^{a}$ School of Chemistry, University of Bristol, Bristol, UK.

E-mail: charl.faul@bristol.ac.uk

${ }^{b}$ School of Molecular Science and Engineering, VISTEC, Thailand gated/aromatic and non-conjugated/aliphatic. Highly crosslinked pPI networks are advantageous over other porous materials owing to the excellent physical and chemical properties such as high mechanical, chemical and thermal stabilities, radiation resistance and high surface areas. Owing to their unique properties, PIs have shown great potential applications for addressing current energy and environmental global challenges. Specifically, pPIs can be utilised in gas

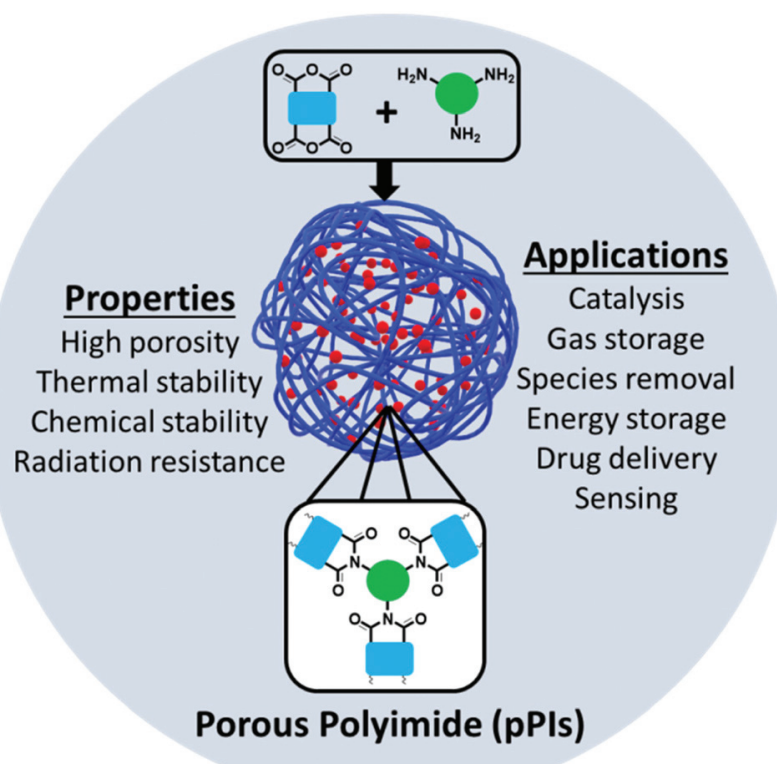

Fig. 1 Porous polyimide properties and applications. 
adsorption and separation, electrical energy storage, heterogeneous catalysis, drug delivery, sensor, and species removal from aqueous environment.

This review covers the broader field of crosslinked and porous PIs, i.e., pPIs, with a specific focus on the monomer design, synthetic advances and the exploration of function and potential applications. The content covers materials published since 2010, and considers amorphous, crystalline and gelatinous crosslinked pPIs, thus ensuring a range of applications and properties demonstrated in each are discussed. Non-crosslinked PIs are not discussed in this review, and the authors refer readers to other reviews and studies that address this topic in detail. $5,6,8,13,14$

\section{Monomer structure}

The properties of polymers are inextricably related to the choice of monomers used for their synthesis. In the case of polyimides, polytopic amines and anhydrides are reacted exploiting several strategies to produce the desired crosslinked and porous pPIs. The structures of amine monomers are shown in Fig. 2, organised according to the number of amino moieties in the monomers (and hence the overall geometry of the formed pPIs, see section 3.2.1), grouped into mono (D1), di- (A1-16), tri- (B1-14) and tetra- (C1-8) amine units; the anhydrides are provided in Fig. 3 (L1-26). To react this wide range of monomers several synthetic strategies have been applied, including solvothermal, ionothermal, interfacial synthetic approaches (exhaustively described in a recent review by Zhang et al. ${ }^{15}$ and, therefore, not discussed in detail here). The authors of the latter work described also how the choice of monomers affected the geometry of the polymeric skeleton, however they only focused on pPIs in covalent organic framework (COFs) states. In this section we will focus on those cases where the rational design and multi-step synthesis of functional monomers allowed control over the properties of the final polymers in crystalline, amorphous and gelatinous pPIs.

Most amine monomers reported in the literature for pPI syntheses are commercially available and require little to no synthetic modification. Here we focus on those monomers with rational geometric or functional design targeting specific properties (see section 4 and 5). Within the amine monomers reported there are 3 major aspects that are noteworthy:

(1) Amount of reactive amine sites. We have found that a variety of amine monomers with 2,3 or 4 reactive amine sites are available, both commercially and synthetically, and are shown in Fig. 2. The number of reactive sites is closely related to the geometry of the amine, e.g., 2 reactive sites = linear (A1-18), 3 = trigonal pyramidal or planar (B1-14), which has the additional effect of crosslinking (with distinct effects on properties such as surface area and applications such as gas absorption, see section 4.1). For the creation of 4 reactive amine sites, many papers cite the use of tetrahedral starting

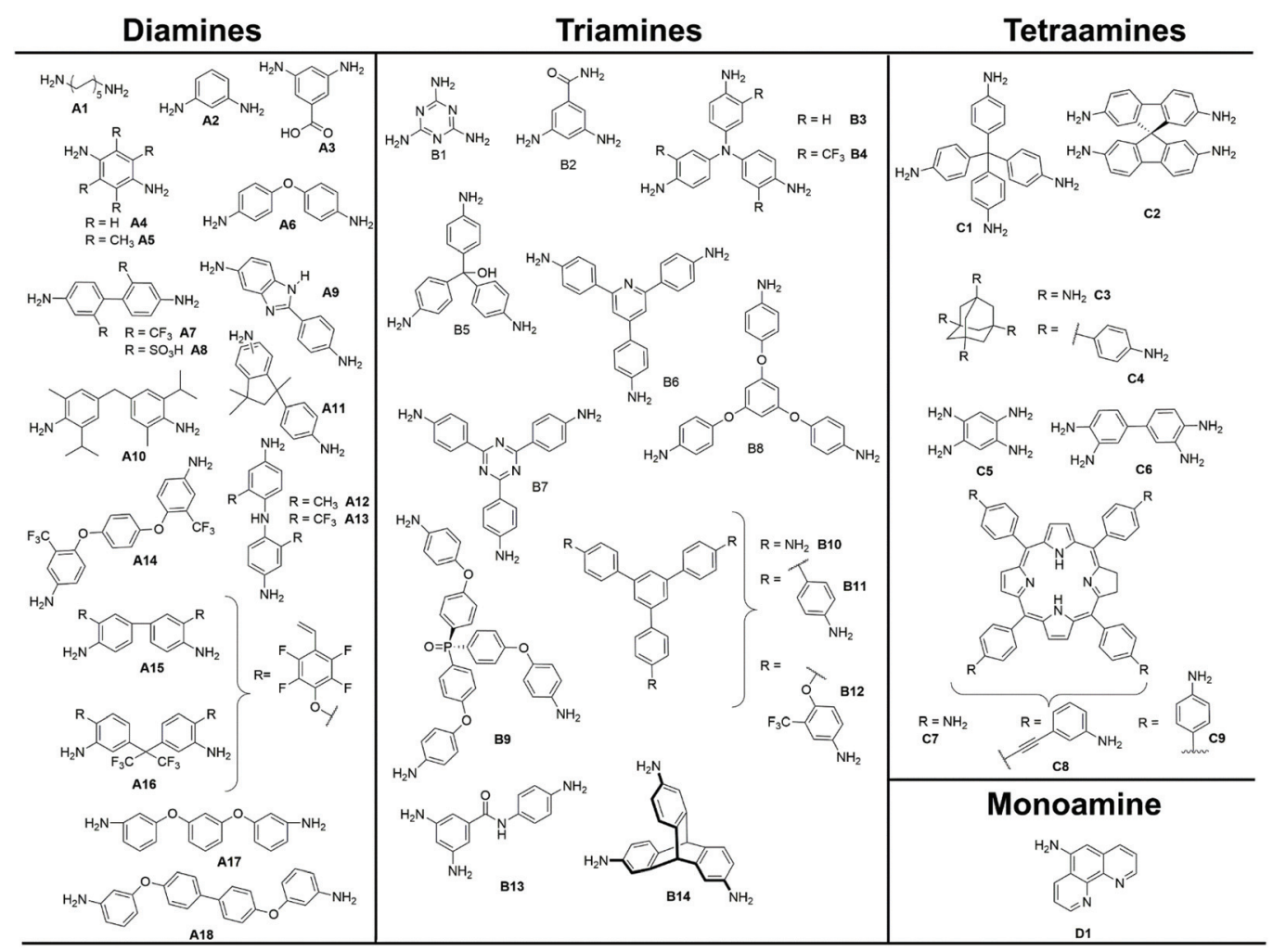

Fig. 2 Amine monomers, grouped into different reactive sites/geometries (di-,tri- and tetra-amines), utilised in the formation of pPI networks covered within this review. 


\section{Anhydrides}
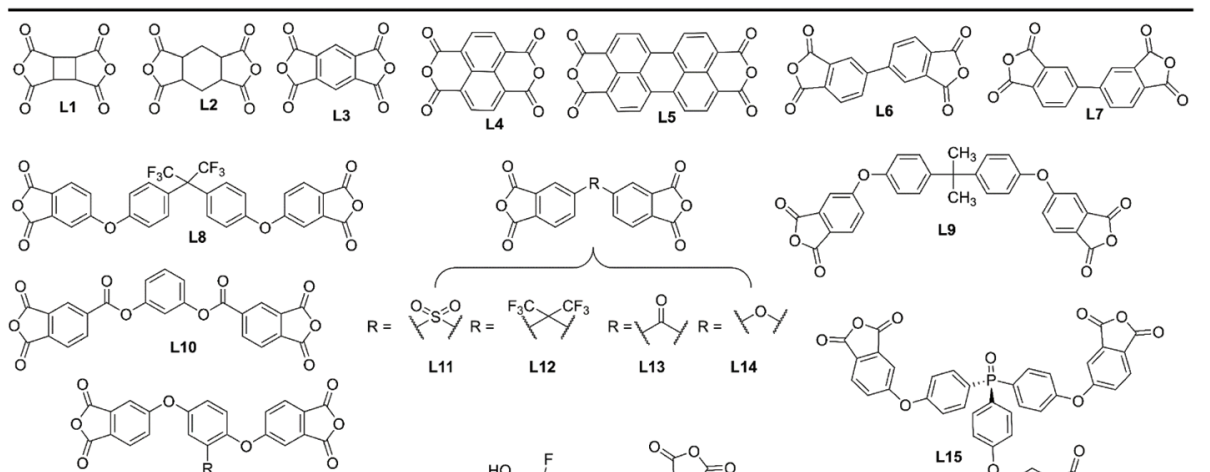

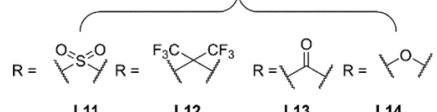

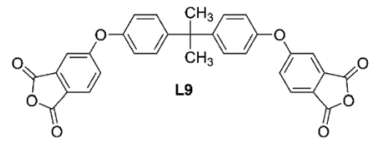

monomers C1-6, or the square planar porphyrin ring (C7-8, both synthetically modified specifically for the purpose of creating pPIs).

(2) Introduction of heteroatoms and functional groups. The introduction of heteroatoms and functional groups into the imide backbone of the polymers have a variety of impacts on the properties and applications (discussed later in sections 3 and 4). In the case of such functionalized amine monomers several are worthy of discussion. With respect to di-reactive amine monomers, the use of commercially available fluorinated aromatic A7 and the synthetically modified A13 and A14 (achieved via a dehydration reaction from the fluorinated ethylene benzene and phenol diamine) are used to include novel functionality. For tri-reactive amine monomers such as B4, B12, and B13, heteroatom-containing functionalities are introduced in the form of $\mathrm{CF}_{3}$ moieties or oxygen ether/ketone linkages. For the monomer B4 multistep synthesis is required; firstly, 4-nitro-3-(trifluoromethyl)aniline and 4-chloro-1-nitro-2(trifluoromethyl)benzene were coupled and the intermediate reduced in the presence of palladium and hydrazine hydrate by Song et al. ${ }^{16}$ In the case of monomers with additional nitrogen heteroatoms (with respect to those involved in the imide linkage), B7 was synthesised by Liebl et al. ${ }^{17}$ from a two-step synthetic procedure involving the trimerisation of 1-bromo-4cyanobenzene in the presence of $\mathrm{CF}_{3} \mathrm{SO}_{3} \mathrm{H}$, followed by a nucleophilic substitution reaction in the presence of $\mathrm{Pd}(\mathrm{dba})_{2}$.

(3) Introduction of cross-linkable structures or moieties in the monomers. Modifications of the monomers, to bear crosslinkable groups, lead to the formation of networks with improved control over their microporous structures (which has a direct effect on sorption and separation applications as discussed in section 4.1). Perhaps the best examples of these are found in the porphyrin-based tetraamine monomer C8, synthesised by Shi et al. ${ }^{18}$ Here $\mathbf{C 8}$ was functionalised with a cross-linkable ethynyl functionality in a two-step synthetic procedure (condensation and oxidation of 4-bromobenzaldehyde and pyrrole in the presence of acetic anhydride and propionic acid). Further examples can be found in the linear fluorinated diamines A15 and A16, modified with ethylene functionalities for post-polymerisation crosslinking. In the cases of nonalkene or alkyne cross-linkable moieties the triamines B2 (synthesised from an addition-elimination reaction between 3,5dinitrobenzoylchloride followed by $-\mathrm{NO}_{2}$ reduction in the presence of $\mathrm{Pd} / \mathrm{C}$ ) and $\mathbf{B 1 3}$ (synthesised from an acylation reaction between 3,5-dinitro benzoylchloride and 4-nitroaniline, followed by reduction with hydrazine hydride in the presence of Pd/C by Rangel Rangel et al. ${ }^{19}$ ) have also been employed.

Anhydride monomers typically possess two reactive sites (especially with benzene L3, naphthalene L4 and perylene L5 linkers). A few exceptions are the use of the mono reactive anhydrides such as L22, used as endcaps by Li et $a l^{20}$ to control polymerisation.

The majority of variations for this monomer are seen in the introduction of heteroatom and functional groups and crosslinkable moieties;

(1) Introduction of heteroatoms and functional groups. The commercially available di-linkers $\mathbf{L 8}$ and $\mathbf{L 1 2}$ have been used to introduce fluorine (useful for increasing hydrophobicity, see section 4 and 5), whereas the porphyrin-based L20 was synthesised in a multistep procedure by Shultz et al. ${ }^{21}$ (involving 


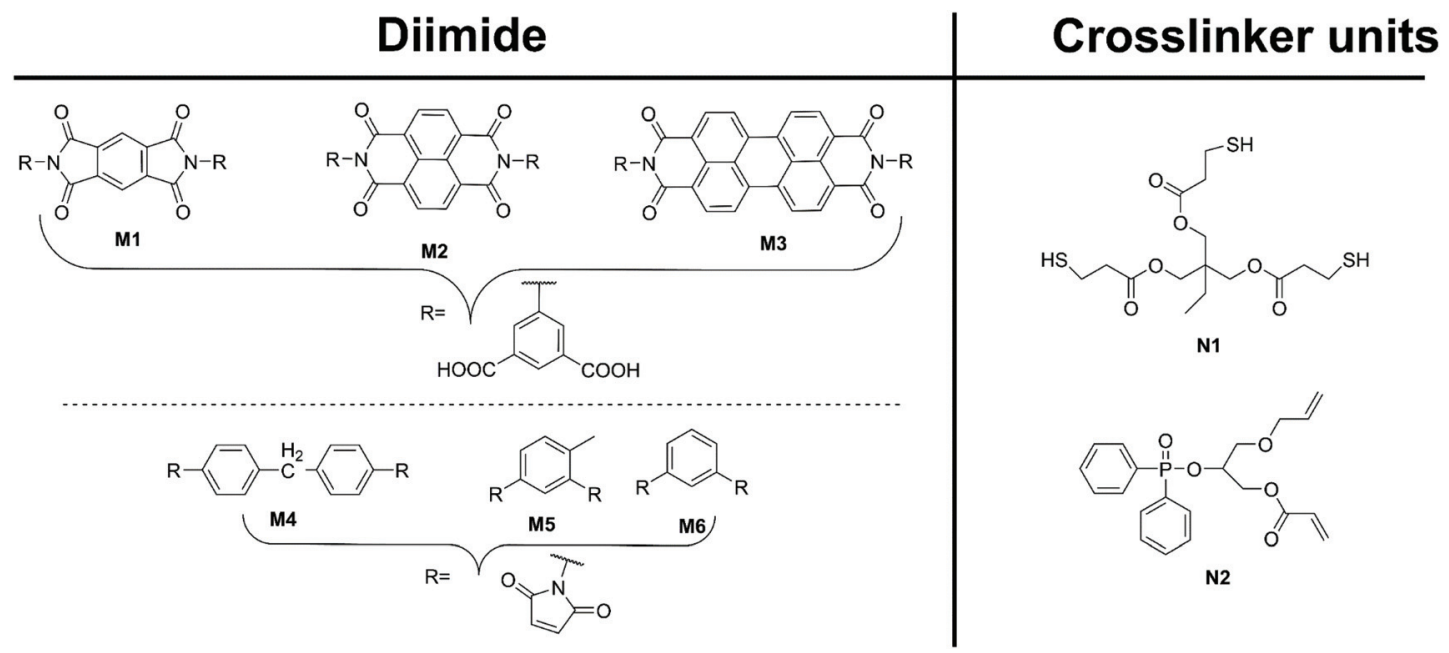

Fig. 4 Preformed diimides M1-6 (left) and crosslinker units (right) utilised in pPI formation in ref. 23-25.

the formation of dimethyl 4-carboxaldehydephthalate and cyclisation with 5-pentafluorophenyl dipyrromethane in the presence of $\mathrm{BF}_{3} \cdot \mathrm{Et}_{2} \mathrm{O}$ and $\mathrm{DDQ}$ ) to introduce fluorine, porphyrin and phenol functionalities. ${ }^{21}$ Anhydrides L9, L10, L13 and L14 are commercially available and used to introduce oxygen into the polyimide backbone, an important addition to influence gas absorption (see section 4.1).

(2) Introduction of cross-linkable structures and moieties in the monomers. Shi et al. ${ }^{18,22}$ have synthesised a range of anhydride monomers containing two cross linkable pendant alkynyl functionalities, L18, L19 and L21, and crosslinked them with amine monomers bearing the alkynyl functionalities (A15 and A16).

Several preformed diimide-containing monomers are documented in the literature and shown in Fig. 4. Roy et al. ${ }^{23}$ synthesised a range of aromatic-based diimide monomers M1-3, from dianhydrides L2-4, respectively, via condensation of 5 -aminoisophthalic acid. The formed diimide, functionalised with dicarboxylic acids, was then condensed with the tetraamine monomers $\mathbf{C 5}$ and $\mathbf{C 6}$ to produce benzimidazole linked pPIs. Lu et $a .^{24}$ and Zhu et al. ${ }^{25}$ condensed maleic anhydride with the appropriate diamine linker to yield the preformed monomer diimides M4-6. Lu et al. $^{24}$ then used diimide M4 and crosslinkers $\mathbf{N} 1$ and $\mathbf{N} 2$ to generate pPIs via click reactions. Finally, Zhu et al. ${ }^{25}$ used preformed diimides M4-6 to generate pPIs via homo-thermal coupling.

\section{Properties}

\subsection{Thermal stability}

Crosslinked pPIs present excellent thermal stabilities, making them suitable for applications such as gas capture in hightemperature environments (e.g. industrial flue-gas outlets), battery and electrode environments or as protective coatings. ${ }^{79}$ Weight loss above $400{ }^{\circ} \mathrm{C}$ can often be attributed to imidisation of unreacted amic acid groups (from anhydride ring opening but failed imide formation) and water loss. ${ }^{45}$ In many cases in the literature, temperatures of degradation $\left(T_{\mathrm{deg}}\right)$ and char yields (wt\% remaining after heating to $800{ }^{\circ} \mathrm{C}$ ) are not reported. In this review we have attempted to calculate those values from thermo gravimetric analysis (TGA) graphs (utilising ImageJ image analysis software) that were not calculated in the original literature and display these generated values in Table 2 alongside those reported.

Conjugated pPIs show typical degradation temperatures between $400-600{ }^{\circ} \mathrm{C}(10 \mathrm{wt} \%$ loss), with the highest stabilities reported by Shi et al., ${ }^{18,22,50,52}$ Song et al., ${ }^{16,60,61,68}$ and Yao et $a .^{37,40}$ (each slightly above $600{ }^{\circ} \mathrm{C}$ ). Conjugated pPIs quite often exhibit a decrease in $T_{\mathrm{deg}}$ when increasing the weight percentage of heteroatoms in the network, as seen, for example, in the studies by Wang et al. ${ }^{28,30}$ with the $T_{\mathrm{deg}}$ increasing with increasing carbon-based dianhydride monomer linker units $\mathbf{L} 3$ and $\mathbf{L 4}$ (although the reasons behind this trend were not investigated by the authors). The introduction of post-polymerisation crosslinking units into pPI networks tends to lead to an increase in pPI thermal stability (with respect to $T_{\mathrm{deg}}$ ) after crosslinking. However, if the crosslinking moieties lead to an increased heteroatom content, a decrease in thermal stability can be observed (see the effect of the introduction of the amide crosslinker unit $\mathbf{B} 2$ by Hasegawa et $\left.a l^{31}\right)$. Interestingly, very little variation in thermal stabilities of conjugated pPI networks is observed when varying the molar ratio of amine centres on the starting monomers from tri- or tetra-amines (see Rao et al. ${ }^{38}$ utilizing the tetra-armed amine $\mathbf{C 1}$, and Shi et al. ${ }^{22}$ using the porphyrin-based tetramines $\mathbf{C 7}$ and $\mathbf{C 8}$ ). Perhaps the most interesting take on control over the thermal properties of conjugated pPI networks is found in the study by Qiao et al. ${ }^{79}$ where they investigated polyimide aerogels. Here frustrated pPI chain growth is found to leave pendant carboxylic acid groups from the anhydride monomer L8, that are then crosslinked post polymerisation (by addition of triethyl amine) under supercritical $\mathrm{CO}_{2}$ to control $T_{\mathrm{deg}}$ via the degree of crosslinking. 
Table 1 Nomenclature for reported pPIs, constituent monomers and references

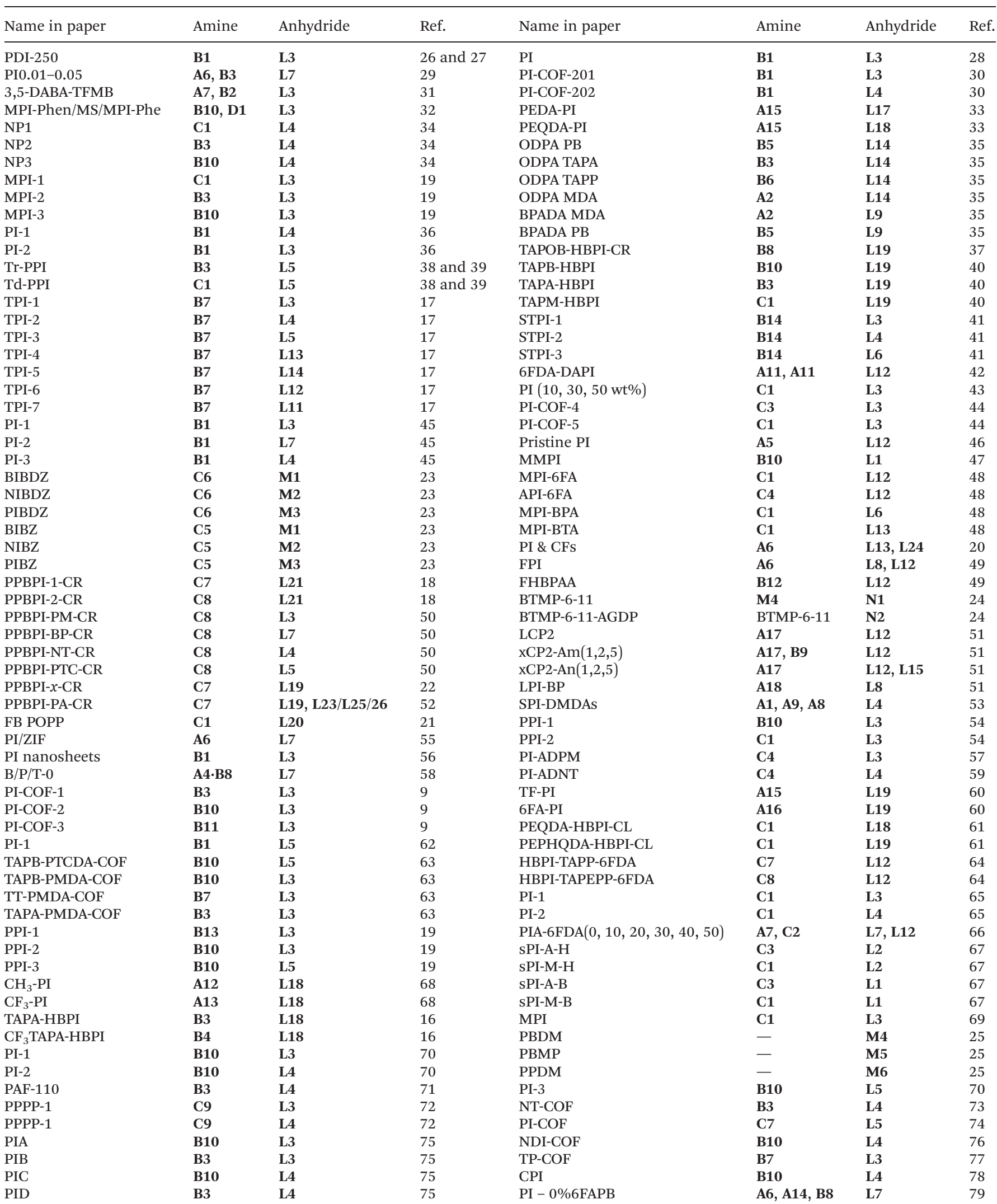


Table 2 Showing $T_{\text {deg }}$ of pPls from TGA under nitrogen and char yields at $800{ }^{\circ} \mathrm{C}$, where * = estimated by the authors from TGA traces utilising image J image analysis software, and \# = char yield at $700^{\circ} \mathrm{C}$

\begin{tabular}{|c|c|c|c|c|c|c|c|}
\hline Name in paper & $T_{\mathrm{deg}}\left({ }^{\circ} \mathrm{C}\right)$ & Char (wt\%) & Ref. & Name in paper & $T_{\text {deg }}\left({ }^{\circ} \mathrm{C}\right)$ & Char (wt\%) & Ref. \\
\hline MPI-1 & 530 & 57.4 & 19 & TAPA-HBPI-CR & $500^{*}$ & $60^{*}$ & 37 \\
\hline MPI-2 & 530 & 53.0 & 19 & TAPA-HBPI-GEL & $600^{*}$ & $60^{*}$ & 37 \\
\hline MPI-3 & 530 & 59.3 & 19 & TAPM-HBPI & $450^{*}$ & $60^{*}$ & 37 \\
\hline PI-COF-1 & 520 & $60^{*}$ & 9 & TAPM-HBPI-CR & $530^{*}$ & $60^{*}$ & 37 \\
\hline PI-COF-2 & 535 & $60^{*}$ & 9 & TAPM-HBPI-GEL & $580^{*}$ & $60^{*}$ & 37 \\
\hline PI-COF-3 & 530 & $60^{*}$ & 9 & TAPOB-HBPI & $500^{*}$ & $70^{*}$ & 37 \\
\hline TFMB & 537 & - & 31 & TAPOB-HBPI-CR & $550^{*}$ & $75^{*}$ & 37 \\
\hline 3,5-DABA (20)TFMB (80) & 520 & - & 31 & TAPOB-HBPI-GEL & $600^{*}$ & $60^{*}$ & 37 \\
\hline 3,5-DABA (50)TFMB (50) & 489 & - & 31 & STPI-1 & $610^{*}$ & $5^{*}$ & 41 \\
\hline 3,5 -DABA (80)TFMB (20) & 467 & - & 31 & STPI-2 & $580^{*}$ & $50^{*}$ & 41 \\
\hline m-PDA (20)TFMB (80) & 527 & - & 31 & STPI-3 & $600^{*}$ & $60^{*}$ & 41 \\
\hline m-PDA (50)TFMB (50) & 536 & - & 31 & PI-COF-4 & 450 & $40^{*}$ & 80 \\
\hline m-PDA (80)TFMB (20) & 532 & - & 31 & PI-COF-5 & 460 & $42^{*}$ & 80 \\
\hline PAA0.03 & $200^{*}$ & $30^{*}$ & 29 & BI-PEG2-xPI & $510^{*}$ & - & 46 \\
\hline PI0.03 & 550 & 50 & 29 & BI-PEG3-xPI & $510^{*}$ & - & 46 \\
\hline NPI1 & 480 & 50.0 & 34 & BI-PEG4-xPI & $500^{*}$ & - & 46 \\
\hline NPI 2 & 485 & 46.7 & 34 & BI-PEG6-xPI & $450^{*}$ & - & 46 \\
\hline NPI 3 & 490 & 64.7 & 34 & MPI-6FA & $550^{*}$ & $50^{*}$ & 48 \\
\hline PI1 & 400 & & 36 & MPI-BTA & $560^{*}$ & $55^{*}$ & 48 \\
\hline PI 1 & 400 & 45 & 62 & MPI-BPA & $610^{*}$ & $58^{*}$ & 48 \\
\hline PI 2 & 405 & 45 & 62 & API-6FA & $550^{*}$ & $53^{*}$ & 48 \\
\hline PI-1-C & & 68 & 62 & PI 300 & - & - & 20 \\
\hline TPI1 & 419 & - & 17 & CF 600 & - & 73 & 20 \\
\hline TPi2 & 456 & - & 17 & CF 900 & - & 65 & 20 \\
\hline TPI3 & 342 & - & 17 & CF 1200 & - & 55 & 20 \\
\hline TPI4 & 427 & - & 17 & CF 1500 & - & 47 & 20 \\
\hline TPI5 & 421 & - & 17 & FPI & 542 & $60^{*}$ & 49 \\
\hline TPI6 & 396 & - & 17 & FPI/FHBPI-5\% & 530 & $58^{*}$ & 49 \\
\hline TPI7 & 450 & - & 17 & FPI/FHBPI-10\% & 528 & $58^{*}$ & 49 \\
\hline PI1 & 410 & $10^{*}$ & 45 & FPI/FHBPI-15\% & 524 & $57^{*}$ & 49 \\
\hline PI2 & 350 & $0^{*}$ & 45 & FPI/FHBPI-20\% & 519 & $57^{*}$ & 49 \\
\hline PI3 & 350 & $30^{*}$ & 45 & FPI/FHBPI-25\% & 516 & $56^{*}$ & 49 \\
\hline PI - 0\%6FAPB & 591 & $T_{\mathrm{g}} 202.1$ & 79 & FHBPI & 514 & $55^{*}$ & 49 \\
\hline PI - 25\%6FAPB & 589 & $T_{\mathrm{g}} 221.6$ & 79 & BTMP-6-AGDP & 328 & 30 & 24 \\
\hline PI - 37.5\%6FAPB & - & $T_{\mathrm{g}} 234.3$ & 79 & BTMP-9-AGDP & 327 & 32 & 24 \\
\hline PI - 50\%6FAPB & 589 & $T_{\mathrm{g}} 259.2$ & 79 & BTMP-11-AGDP & 326 & 34 & 24 \\
\hline PPI1 & 560 & - & 19 & PPI-1 & 570 & $62^{*}$ & 54 \\
\hline PPI2 & 570 & - & 19 & PPI-1-NH2 & 405 & $54^{*}$ & 54 \\
\hline PPI3 & 525 & - & 19 & PPI-2 & 540 & $65^{*}$ & 54 \\
\hline Tr-PPI & $550^{*}$ & $60^{*}$ & 38 & PPI-2-NH2 & 410 & $35^{*}$ & 54 \\
\hline Td-PPI & $450^{*}$ & $60^{*}$ & 38 & PI-ADNT & $600^{*}$ & - & 59 \\
\hline BIBDZ & $100^{*}$ & $70^{*}$ & 23 & PI-NO2-1 & $400^{*}$ & - & 59 \\
\hline PIBDZ & $100^{*}$ & $60^{*}$ & 23 & PI-NO2-2 & $400^{*}$ & - & 59 \\
\hline NIBDZ & $100^{*}$ & $65^{*}$ & 23 & PI-NO2-3 & $400^{*}$ & - & 59 \\
\hline BIPZ & $100^{*}$ & $70^{*}$ & 23 & TF-PI & $500^{*}$ & $45^{*}$ & 60 \\
\hline PIBZ & $100^{*}$ & $60^{*}$ & 23 & TF-PI-CL & $560^{*}$ & $65^{*}$ & 60 \\
\hline NIBZ & $100^{*}$ & $68^{*}$ & 23 & 6FA-PI & $500^{*}$ & $45^{*}$ & 60 \\
\hline PPBPI-H & $520^{*}$ & $65^{*}$ & 22 & 6FA-PI-CL & $550^{*}$ & $60^{*}$ & 60 \\
\hline PPBPI-Mn & $580^{*}$ & $75^{*}$ & 22 & PI-1 & 588 & $72^{*}$ & 81 \\
\hline PPBPI-Fe & $518^{*}$ & $66^{*}$ & 22 & PI-2 & 519 & $65^{*}$ & 81 \\
\hline PPBPIR-H CR & $522^{*}$ & $66^{*}$ & 22 & PIA/6FDA-0 & 593 & $60^{*}$ & 82 \\
\hline PPBPI-Mn-Cr & $520^{*}$ & $68^{*}$ & 22 & PIA/6FDA-10 & 573 & $59^{*}$ & 82 \\
\hline PPBPI-Fe-Cr & $580^{*}$ & $70^{*}$ & 22 & PIA/6FDA-20 & 565 & $59^{*}$ & 82 \\
\hline PPBPI-PA & $580^{*}$ & $60^{*}$ & 52 & PIA/6FDA-30 & 551 & $59^{*}$ & 82 \\
\hline PPBPI-PEPA & $600^{*}$ & $70^{*}$ & 52 & PIA/6FDA-40 & 550 & $59^{*}$ & 82 \\
\hline PPBPI_PENA & $560^{*}$ & $68^{*}$ & 52 & PIA/6FDA-50 & 536 & $58^{*}$ & 82 \\
\hline PPBPI-PA-CR & $600^{*}$ & $68^{*}$ & 52 & sPI_A-H & $540^{*}$ & $52^{*}$ & 67 \\
\hline PPBPI-PEPA-CR & $560^{*}$ & $70^{*}$ & 52 & sPI-M-H & $530^{*}$ & $47^{*}$ & 67 \\
\hline PPBPI-PENA-CR & $380^{*}$ & $60^{*}$ & 52 & sPI_A-B & $430^{*}$ & $48^{*}$ & 67 \\
\hline TAPA-HBPI & $510^{*}$ & $54^{*}$ & 16 & sPI-M-B & $420^{*}$ & $48^{*}$ & 67 \\
\hline TAPA-HBPI-CL & $610^{*}$ & $65^{*}$ & 16 & MMPI & $520^{*}$ & $60^{*}$ & 83 \\
\hline CF3TAPA-HBPI & $510^{*}$ & $55^{*}$ & 16 & LCP2 & 526 & - & 51 \\
\hline CF3TAPA-HBPI-CL & $600^{*}$ & $65^{*}$ & 16 & xCP2-Am1 & 514 & - & 51 \\
\hline PI-1 & 473 & - & 70 & xCP2-Am2 & 511 & - & 51 \\
\hline PI-2 & 502 & - & 70 & xCP2-Am5 & 518 & - & 51 \\
\hline PI-3 & 490 & - & 70 & xCP2-An1 & 519 & - & 51 \\
\hline PI & $380^{*}$ & - & 28 & xCP2-An2 & 518 & - & 51 \\
\hline
\end{tabular}


Table 2 (Contd.)

\begin{tabular}{|c|c|c|c|c|c|c|c|}
\hline Name in paper & $T_{\text {deg }}\left({ }^{\circ} \mathrm{C}\right)$ & Char (wt\%) & Ref. & Name in paper & $T_{\mathrm{deg}}\left({ }^{\circ} \mathrm{C}\right)$ & Char (wt\%) & Ref. \\
\hline PI-COF 201 & $380^{*}$ & $10^{*}$ & 30 & xCP2-An5 & 518 & - & 51 \\
\hline PI-COF 202 & $420^{*}$ & $10^{*}$ & 30 & LPI-BP & - & - & 51 \\
\hline PEDA-PI & $500^{*}$ & $55^{*}$ & 33 & CSPI-DMDA $(1: 3)$ & $340^{*}$ & $49^{*}$ & 53 \\
\hline PEDA-PI-CL & $550^{*}$ & $68^{*}$ & 33 & CSPI-DMDA $(1: 1)$ & $340^{*}$ & $52^{*}$ & 53 \\
\hline PEQDA-PI & $480^{*}$ & $50^{*}$ & 33 & CSPI-DMDA $(3: 1)$ & $330^{*}$ & $40^{*}$ & 53 \\
\hline PEQDA-PI-CL & $550^{*}$ & $67^{*}$ & 33 & PAF-110 & $530^{*}$ & $5^{*}$ & 71 \\
\hline TAPB-HBPI & $520^{*}$ & $75^{*}$ & 40 & MPI-0-10 & 363 & $55^{*}$ & 84 \\
\hline TAPB-HBPI-CR & $570^{*}$ & $75^{*}$ & 40 & MPI-30-10 & 485 & $60^{*}$ & 84 \\
\hline TAPB-HBPI-GEL & $570^{*}$ & $70^{*}$ & 40 & MPI-40-10 & 465 & $60^{*}$ & 84 \\
\hline TAPA-HBPI & $510^{*}$ & $60^{*}$ & 40 & MPI-50-10 & 443 & $60^{*}$ & 84 \\
\hline PIA & 535 & $65^{*}$ & 75 & MPI-60-10 & 452 & $60^{*}$ & 84 \\
\hline PIB & 525 & $60^{*}$ & 75 & MPI-70-10 & 476 & $60^{*}$ & 84 \\
\hline PIC & 535 & $65^{*}$ & 75 & MPI-100-10 & 391 & $61^{*}$ & 84 \\
\hline PID & 520 & $50^{*}$ & 75 & MPI-60-5 & - & - & 84 \\
\hline CPI & $275^{*}$ & $55^{*}$ & 78 & MPI-60-7 & 348 & $60^{*}$ & 84 \\
\hline NDI-COF & 500 & 60 & 76 & MPI-60-9 & 490 & $61^{*}$ & 84 \\
\hline PI-COF & 500 & 60 & 74 & MPI-60-11 & 492 & $62^{*}$ & 84 \\
\hline PPPP-1 & 560 & 70 & 72 & MPI-60-13 & 503 & $63^{*}$ & 84 \\
\hline PPPP-2 & 570 & 70 & 72 & & & & \\
\hline
\end{tabular}

The majority of conjugated pPIs reported in this review are highly crosslinked amorphous materials; thermal analysis such as dynamic scanning calorimetry (DSC) to examine thermal transitions before the $T_{\mathrm{deg}}$ are thus largely unreported or unexplored. An exception can be found in the pPIs synthesised by Hasegawa et al. ${ }^{31}$ where both DSC and dynamic mechanical analysis are used to demonstrate the manipulation of glass transition temperatures $\left(T_{\mathrm{g}}\right)$ by post-polymerisation crosslinking of pPIs utilizing the amide crosslinker unit $\mathbf{B 2}$. Further to this exception, Qiao et al. ${ }^{79}$ show manipulation of $T_{\mathrm{g}}$ via introduction of $\mathrm{CF}_{3}$ side groups (to increase the steric hinderance and free movement of chains, hence increase in $T_{\mathrm{g}}$ ), using the amine monomer A14 into their polyimide aerogels. Song et al. ${ }^{68}$ and Shi $e t a .^{22}$ utilised post-polymerisation cross-coupling of alkynes present in the anhydride monomers L18 and L19. In the majority of cases DSC is primarily used for verification of post-polymerisation crosslinking, with exotherms being recorded in the first heating scan but absent in the second.

The properties of pPIs beyond their $T_{\mathrm{deg}}$ temperatures were explored by Liao et al. ${ }^{62}$ using the charred product after heating beyond $T_{\mathrm{deg}}$ to form 'derived carbons' (from pPIs of B1 and L5). They found both increased surface area and $\mathrm{CO}_{2}$ uptakes for these derived carbons with respect to the noncharred pPIs (see further discussion on gas absorption properties). This leads to the question whether higher $T_{\mathrm{deg}}$ is desirable when trying to access char products with enhanced absorption properties efficiently. ${ }^{31}$ The mechanisms of charring and carbonisation have also been explored by Li et al., ${ }^{20,49}$ using Raman, XPS spectroscopy and XRD diffractometry to analyse the products post carbonisation. They concluded that 'the decomposition of imide rings and the breakage of the ether oxygen in the bridging part of polyimide' are responsible for charring, leading to the proposition that increased heteroatom content can facilitate carbonisation (and hence a decrease in $T_{\mathrm{deg}}$ ). It is evident that carbonisation (and its ben- eficial effects on properties such as surface area or gas absorption, specifically $\mathrm{CO}_{2}$ uptake) are relatively unexplored in the literature to date and is an area for further future exploration and development.

Many of the reported non-conjugated pPIs show similar properties and trends to the conjugated pPIs summarized above. However, there are some aspects to be highlighted in this section. Studies for non-conjugated pPIs tend to conclude that $T_{\mathrm{deg}}$ as well as char yields in $\mathrm{N}_{2}$ tend to be optimized when using pPIs with the least amount of heteroatoms within the network (see, for example, Li et al. ${ }^{19,34,36}$ ). Rangel Rangel et al. ${ }^{19}$ demonstrated that functionalization of their pPIs with nitro groups (for catalysis applications, see section 4.2) results in a decrease in thermal stability, from the $540-570{ }^{\circ} \mathrm{C}$ to the low $400{ }^{\circ} \mathrm{C}$ region. Similar results were observed by Shen et al. ${ }^{59}$ investigating a tetra-armed pPI with a high thermal stability of $621{ }^{\circ} \mathrm{C}$ that experiences a considerably drop in stability after nitration to $370{ }^{\circ} \mathrm{C}$ (as a result of $\mathrm{C}-\mathrm{NO}_{2}$ cleavage throughout the pPI). However, in contrast to this behaviour, Wang et al. ${ }^{81}$ found that a change in anhydride linker from benzene $\mathbf{L} 3$ to naphthalene L4 (an increase in carbon percentage as well as conjugation) in their non-conjugated pPIs resulted in a drop in the $T_{\mathrm{deg}}$. Lu et al. $^{24}$ also showed how increased thiol linkages in pPIs (present from linker N2) can result in increased $T_{\mathrm{deg}}$ and increased char yields. Finally, Wu et al. ${ }^{82}$ found, counterintuitively, a decrease in $T_{\mathrm{deg}}$ with increasing crosslinking percentage (and hence increased carbon-carbon bond formation), with no further explanation provided.

The majority of crosslinked pPIs do not demonstrate melts or glass transitions $\left(T_{\mathrm{g}}\right)$. However, Lu et $a .^{24}$ showed how control over the length of thiol linkages (N2) in pPIs allow manipulation of the $T_{\mathrm{g}}$, with a maximum of $59{ }^{\circ} \mathrm{C}$ appearing for moieties with 9 thiol linkers per linker unit. It is worth nothing that although this polymer is classified here as a pPI, the thiols are used for the formation of the final crosslinked product from the preformed diimide M2. The manipulation of 
the $T_{\mathrm{g}}$ of the final product is important as it has been linked to a deformation temperature. Below this temperature, the polymer will hold a deformed shape and above the polymer recovers to its original shape (i.e., displaying shape memory function) due to the high degree of crosslinking and stability. Li et al. $^{49}$ use blends of both linear (from A12 and L12) and crosslinked (using B12 to crosslink) fluorinated pPIs to manipulate both $T_{\mathrm{deg}}$ and $T_{\mathrm{g}}$. A decrease of $T_{\mathrm{deg}}$ is observed with increasing crosslinked content in the blend, attributed to the increase in terminal hydrides in the crosslinked structure and hence increased post-polymerisation carbonisation. Both the linear and crosslinked pPIs demonstrate $T_{\mathrm{g}}$ values of approximately $260{ }^{\circ} \mathrm{C}$; mixing provides a route to manipulation of the $T_{\mathrm{g}}$, with a maximum value of $T_{\mathrm{g}}$ realized at $5 \mathrm{wt} \%$ crosslinker (as confirmed by dynamic mechanical analysis).

\subsection{Porosity}

We have found several trends in the surface areas of pPIs, and discuss below the most relevant and important factors influencing this important property of this class of porous materials:

3.2.1. Effect of geometry of starting material on porosity. Specifically, a number of groups have explored the influence of $3 \mathrm{D}$ geometry of the cores of pPIs on surface areas and properties. For example, Li et al. ${ }^{34}$ synthesised three pPIs with three different core amines; the tetra-amine $\mathbf{C 1}$ (tetrahedral, to give NPI-1) and tri-amines B3 and B10 (trigonal pyramidal, NPI-2 and trigonal planar NPI-3, respectively), whilst keeping the dianhydride linker (L4) the same. This study found the that highest pore volumes, as well as surface areas, were generated with the tetrahedral core (C1) due to its 3D shape, which prevented the pPIs from close packing (surface areas of NPI-1, 2, 3 are 721,291 , and $373 \mathrm{~m}^{2} \mathrm{~g}^{-1}$, respectively, see Table 3). Similar studies were undertaken by the same author using the same cores but a shorter linker (L3). The same trends were observed: the surface area with tetrahedral core was the highest $\left(1454 \mathrm{~m}^{2} \mathrm{~g}^{-1}\right)$ followed by the trigonal pyramidal $\left(814 \mathrm{~m}^{2} \mathrm{~g}^{-1}\right)$ and the trigonal planar core $\left(586 \mathrm{~m}^{2} \mathrm{~g}^{-1}\right.$, see Table 3). The lowest surface area with the trigonal planar core was attributed to formation of $\pi$-stacking and loss of pore volume, thus resulting in lower surface area compared with the tetrahedral and trigonal pyramidal geometry cores.

Surface area and pore size can also be tuned by varying the length and size of the monomer linkers and cores. Rao et al. ${ }^{38}$ reported two pPIs consisting of either tetra-amine C1 (tetrahedral) or tri-amine B3 (trigonal pyramidal), but with a longer anhydride linker L5 (when compared with NPI-1-3 synthesised by Li et al. ${ }^{19,34}$ ). The surface areas were $2213 \mathrm{~m}^{2} \mathrm{~g}^{-1}$ (C1 tetrahedral) and $400 \mathrm{~m}^{2} \mathrm{~g}^{-1}$ (B3 trigonal pyramidal), respectively, which were higher than pPIs synthesised with the shorter dianhydride L4 linker with the same core (see Table 3). ${ }^{34}$ Analogously, Fang et al. ${ }^{9}$ showed that increases in the core size increased the surface area. The condensation of the dianhydride linker L3 with either B10 or B11 (larger core than B3) resulted in a doubling of surface area from $1297 \mathrm{~m}^{2} \mathrm{~g}^{-1}$ to $2346 \mathrm{~m}^{2} \mathrm{~g}^{-1}$ when the core length was increased to contain an extra benzene moiety. The average pore size also increased from $37 \AA$ to $53 \AA$ with this extended architecture (Table 3).

3.2.2. Post-synthesis modification. To ensure the full range of post-synthesis modification strategies are covered, we have included carbonisation, post-polymerisation crosslinking and post-polymerisation chemical functionalisation under the heading of post-synthesis modification. Here we expand on the effects and general trends seen in these three subsections.

3.2.2.1. Carbonisation. It is important to note that uncontrolled post-polymerisation crosslinking in the form of carbonisation is reported to increase the surface area of most conjugated porous networks. Despite this general observation, the pPIs reported in this review have largely not been investigated in regard to the effects of carbonisation on surface area. In the specific case of pPIs we have found that only Liao et al. ${ }^{62}$ investigated this effect, with an increase from $19 \mathrm{~m}^{2} \mathrm{~g}^{-1}$ to $181 \mathrm{~m}^{2}$ $\mathrm{g}^{-1}$ after carbonisation of pPI synthesised from B1 and $\mathbf{L 5}$. Wu et al. ${ }^{55}$ also used carbonisation to crosslink linear PIs (from L7 and A6) to form pPIs, which were blended, in the linear form (pre-carbonisation), with zeolite imidazolate frameworks (ZIF). However, the surface area decreased significantly after carbonisation (from 200-300 $\mathrm{m}^{2} \mathrm{~g}^{-1}$ to $10 \mathrm{~m}^{2} \mathrm{~g}^{-1}$ ); the reasons behind this decrease were not investigated.

3.2.2.2. Post-polymerisation crosslinking. Surface areas can be further tuned via controlled post-polymerisation crosslinking. Shi et al. ${ }^{22}$ synthesised porphyrin-based pPIs (based on amine C7) with a cross-linkable alkynyl group present in the starting anhydride monomer L19. The surface area of the pPIs after crosslinking (without metal absorption) were $733 \mathrm{~m}^{2}$ $\mathrm{g}^{-1}$, significantly higher than the non-crosslinked pPI $\left(167 \mathrm{~m}^{2}\right.$ $\mathrm{g}^{-1}$ see Table 3). Another study by Wang et al. ${ }^{33}$ used an amine monomer A15 bearing a cross-linkable ethynyl group in combination with non-cross-linkable $\mathbf{L 1 7}$ and cross-linkable alkenecontaining $\mathbf{L 1 8}$ dianhydride, respectively. The surface areas of the pPIs from the non-cross-linkable dianhydride was $78 \mathrm{~m}^{2}$ $\mathrm{g}^{-1}$ whilst that using the cross-linkable group was $64 \mathrm{~m}^{2} \mathrm{~g}^{-1}$. After thermal crosslinking, the surface area increased to $399 \mathrm{~m}^{2} \mathrm{~g}^{-1}$ and $604 \mathrm{~m}^{2} \mathrm{~g}^{-1}$, respectively. The increase in surface area was attributed to the crosslinking restricting movement (and hence restricting denser packing) of polymer chains.

3.2.2.3. Post polymerisation chemical functional modification. Rangel Rangel et al. ${ }^{54}$ utilised dianhydride linker L3 and triamine B10 or tetraamine $\mathbf{C 1}$ to synthesize PPI-1 and PPI-2, respectively. PPI-1 and PPI-1 were then functionalised with additional amino groups (via nitration and subsequent reduction), which resulted in a decrease of surface areas from 570 to $405 \mathrm{~m}^{2} \mathrm{~g}^{-1}$ and 540 to $410 \mathrm{~m}^{2} \mathrm{~g}^{-1}$, respectively. Shi et $a .^{22}$ also reported that the metalloporphyrin-based pPIs (from monomers C7 and C8) have lower surface areas than the materials prepared from metal-free cores. The incorporation of metal ions increased the unit mass and blocked the micropores of the polyimide skeleton, leading to a decrease in their surface area from $733 \mathrm{~m}^{2} \mathrm{~g}^{-1}$ to $144 \mathrm{~m}^{2} \mathrm{~g}^{-1}$ for Mn and $172 \mathrm{~m}^{2}$ $\mathrm{g}^{-1}$ for Fe, respectively. It is noteworthy that these values were obtained via post-polymerisation crosslinking; the surface 
Table 3 Porosity properties of pPIs where $S_{\mathrm{BET}}=$ surface area from BET, PV = pore volume, $Q_{\mathrm{st}}=$ isosteric heat of absorption, A: amorphous; C: crystalline; i: at 195 K, 1 bar; ii: at 273 K, 1 bar; iii: at 77 K, 1 bar, iv: 77 K, 30 bar, v: 298 K, 1 bar, *only the highest surface areas are reported

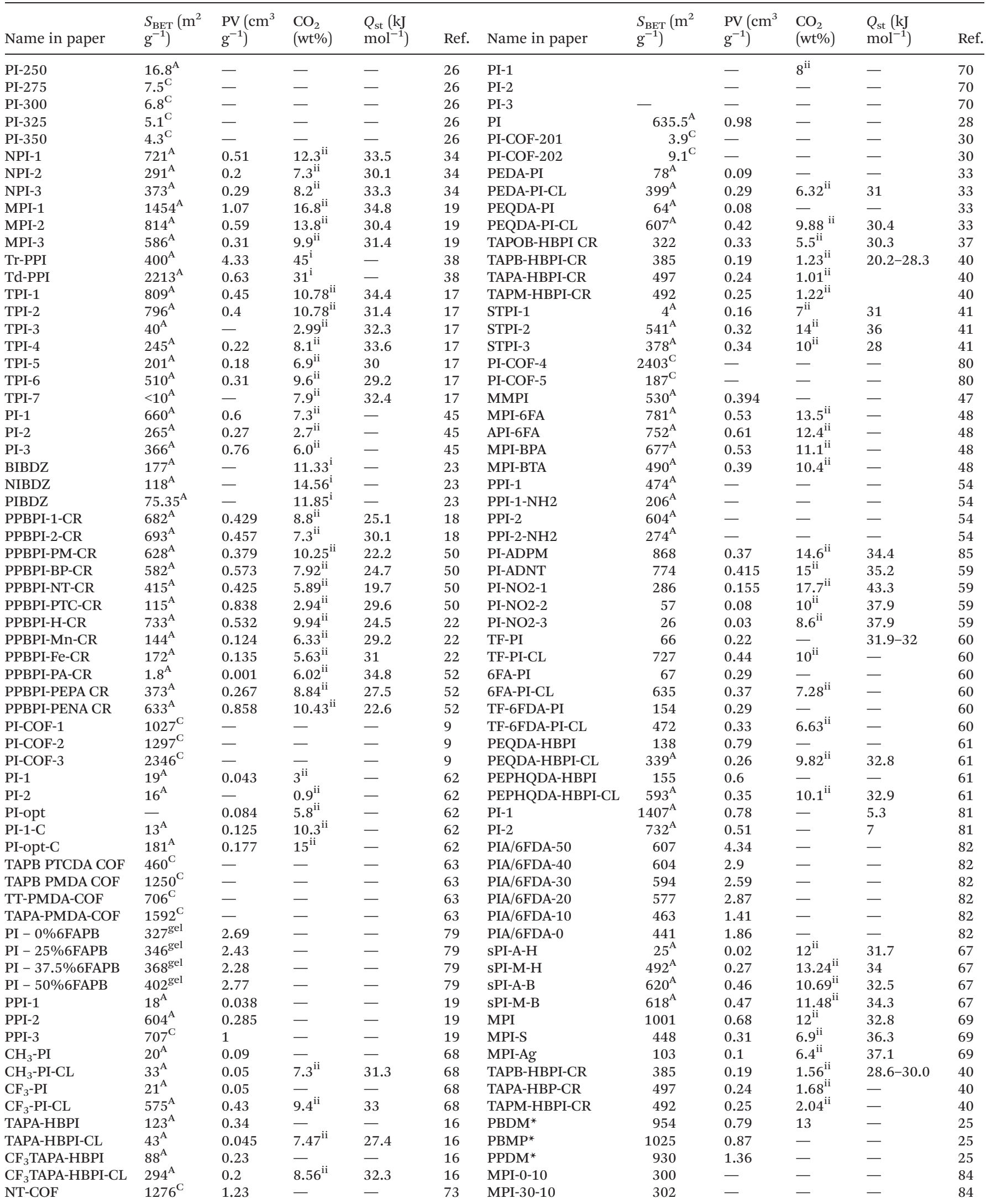


Table 3 (Contd.)

\begin{tabular}{|c|c|c|c|c|c|c|c|c|c|c|c|}
\hline Name in paper & $\begin{array}{l}S_{\mathrm{BET}}\left(\mathrm{m}^{2}\right. \\
\left.\mathrm{g}^{-1}\right)\end{array}$ & $\begin{array}{l}\text { PV }\left(\mathrm{cm}^{3}\right. \\
\left.\mathrm{g}^{-1}\right)\end{array}$ & $\begin{array}{l}\mathrm{CO}_{2} \\
(\mathrm{wt} \%)\end{array}$ & $\begin{array}{l}Q_{\mathrm{st}}(\mathrm{kJ} \\
\left.\mathrm{mol}^{-1}\right)\end{array}$ & Ref. & Name in paper & $\begin{array}{l}S_{\mathrm{BET}}\left(\mathrm{m}^{2}\right. \\
\left.\mathrm{g}^{-1}\right)\end{array}$ & $\begin{array}{l}\text { PV }\left(\mathrm{cm}^{3}\right. \\
\left.\mathrm{g}^{-1}\right)\end{array}$ & $\begin{array}{l}\mathrm{CO}_{2} \\
(\mathrm{wt} \%)\end{array}$ & $\begin{array}{l}Q_{\mathrm{st}}(\mathrm{kJ} \\
\left.\mathrm{mol}^{-1}\right)\end{array}$ & Ref. \\
\hline PI-COF & $894^{\mathrm{C}}$ & 0.47 & - & - & 74 & MPI-40-10 & 303 & - & - & - & 84 \\
\hline PIA & $580^{\mathrm{C}}$ & - & $10^{\mathrm{ii}}$ & - & 75 & MPI-50-10 & 276 & - & - & - & 84 \\
\hline PIB & $760^{\mathrm{C}}$ & - & $12^{\mathrm{ii}}$ & - & 75 & MPI-60-10 & 258 & - & - & - & 84 \\
\hline PIC & $990^{\mathrm{C}}$ & - & $11^{\mathrm{ii}}$ & - & 75 & MPI-70-10 & 250 & - & - & - & 84 \\
\hline PID & $1430^{\mathrm{C}}$ & - & $13^{\mathrm{ii}}$ & - & 75 & MPI-100-10 & 251 & - & - & - & 84 \\
\hline PAF-110 & $910^{\mathrm{C}}$ & 0.59 & - & - & 71 & MPI-60-5 & - & - & - & - & 84 \\
\hline NDI-COF & $1138^{\mathrm{C}}$ & 0.77 & - & - & 76 & MPI-60-7 & 202 & - & - & - & 84 \\
\hline PPPP-1 & $295^{\mathrm{C}}$ & - & - & - & 72 & MPI-60-9 & 226 & - & - & - & 84 \\
\hline PPPP-2 & $301^{\mathrm{C}}$ & - & - & - & 72 & MPI-60-11 & 262 & - & - & - & 84 \\
\hline TP-COF & $960^{\mathrm{C}}$ & - & - & - & 77 & MPI-60-13 & 281 & - & - & - & 84 \\
\hline CPI & 65 & - & - & - & 78 & & & & & & \\
\hline
\end{tabular}

areas compared with the non-crosslinked pPIs were higher by a factor of 10. Yan et al. ${ }^{69}$ also reported that the post-polymerisation chemical modification of pPI MPI (formed from C1 and $\mathbf{L 3}$ ) decreased the surface area from $1001 \mathrm{~m}^{2} \mathrm{~g}^{-1}$ to $448 \mathrm{~m}^{2}$ $\mathrm{g}^{-1}$ after sulfonation (MPI-S), and further to $103 \mathrm{~m}^{2} \mathrm{~g}^{-1}$, after forming a silver-pPI ionically bound complex (MPI-Ag).

3.2.3. Amorphous $v s$. crystalline pPIs. The expected trend is that crystalline (COF) porous pPIs will have higher surface areas than their amorphous counterparts (for a comprehensive review on crystalline polyimides see Zhang et al. ${ }^{15}$ ) and is indeed apparent in the highest surface area reported for the crystalline pPI synthesised by Fang et al. ${ }^{9}$ at $2403 \mathrm{~m}^{2} \mathrm{~g}^{-1}$. This trend was observed where similar pPIs were synthesised with either amorphous or crystalline properties, with the crystalline materials having higher surface areas owing to an increase in uniformity of the pores (see Table 3). Specifically, this trend is demonstrated in the pPIs synthesised using $\mathbf{B} \mathbf{3}$ and $\mathbf{L} \mathbf{3}$ by Fang et al. ${ }^{9}$ in $2014\left(1027 \mathrm{~m}^{2} \mathrm{~g}^{-1}\right)$ and Maschita et al. ${ }^{63}$ in 2020 $\left(1592 \mathrm{~m}^{2} \mathrm{~g}^{-1}\right)$. Crystalline pPIs (in this case, COFs) were produced, yet a similar synthesis by Li et al. ${ }^{86}$ in 2013 produced the analogous amorphous pPI with a reduced surface area $\left(814 \mathrm{~m}^{2} \mathrm{~g}^{-1}\right)$. Furthermore, studies by Jiang et al. ${ }^{71} \mathrm{Lv}$ et al. ${ }^{73}$ and van der Jagt et al. ${ }^{75}$ to form crystalline pPIs from $\mathbf{B} 3$ and L4 gave surface areas of $910 \mathrm{~m}^{2} \mathrm{~g}^{-1}, 1276 \mathrm{~m}^{2} \mathrm{~g}^{-1}$, and $1430 \mathrm{~m}^{2}$ $\mathrm{g}^{-1}$, respectively, in comparison with a surface area of $291 \mathrm{~m}^{2}$ $\mathrm{g}^{-1}$ found for its amorphous counterpart NPI-2 (Li et al. ${ }^{34}$ ). Manipulation of the crystallinity of porous pPIs via synthetic condition variations is clearly demonstrated in pPIs synthesised by Fang et al. ${ }^{9}$ and Maschita et al. ${ }^{63}$ It was found that ionothermally synthesised pPIs demonstrated higher crystallinity and therefore higher surface areas than the solvothermally synthesised analogous counterparts (with lower crystallinity) in these two studies. The trend of higher surface area of PI-COFs over amorphous pPIs was also observed by Fang et al. ${ }^{80} \mathrm{Li}$ et al. ${ }^{86}$ and Wang et al., ${ }^{33}$ each synthesizing pPIs with $\mathbf{L 3}$ and C1. They found surface areas of up to $1876 \mathrm{~m}^{2} \mathrm{~g}^{-1}$ for crystalline materials, with amorphous materials (from the same starting materials) possessing lower surface areas of up to $1407 \mathrm{~m}^{2} \mathrm{~g}^{-1}$.

Outliers to the trend are found for the pPIs synthesised from $\mathbf{L} 3$ and $\mathbf{B} 1$ by Wang et al. ${ }^{28,30}$ where the surface area of the amorphous analogue was significantly higher (by a factor of over 70) than that of the crystalline counterpart (i.e., $635 \mathrm{vs.}$ $9 \mathrm{~m}^{2} \mathrm{~g}^{-1}$ ). Although it is not immediately obvious why higher surface areas were obtained for the amorphous pPI, one of the factors that could contribute to lower surface area for COFs could be the chosen synthesis conditions; specifically, the COF pPI was synthesised by direct heating without any solvent, resulting in potential uncontrolled polymerisation, whereas the amorphous pPI was synthesised in solution (that that might have led to the a higher degree of control in regard to surface area, but less order). A further similar example was presented by Luo et al. ${ }^{45}$ with $\mathbf{~} \mathbf{4}$ and $\mathbf{B 1}$ as starting materials, where the surface area of amorphous materials were higher than that of the crystalline COF analogue synthesised by Wang et al. ${ }^{30}$ However, it is noteworthy that these were the only two cases found where amorphous pPIs possessed higher surface areas than their COF counterparts.

\subsection{Energy storage capabilities and related properties}

Polymers with an extended $\pi$-conjugated backbone and high surface area with excellent microporosity (with an average pore size of $<2 \mathrm{~nm}$ ) are advantageous for electrical energy storage applications. ${ }^{87}$ Conjugation is beneficial with respect to both electrochemical stability and electronic conductivity. ${ }^{36}$ It is to be noted that we are only considering conjugated pPI networks in this section owing to their attractive electronic properties. The electronic properties of non-conjugated pPIs are explored in two recent publications by Tian et al. ${ }^{64}$ and Gao et al. ${ }^{43}$ highlighting attempts to increase conductivity focusing on increasing pPI conjugation, or via addition of conjugated additives.

Batteries and capacitors, as the most common energy storage devices, operate via electric double layer capacitance and pseudo-capacitance mechanisms. In electric double layer capacitance (EDLC), energy is stored and release by a physical ion adsorption-desorption mechanism at the electrode-electrolyte interface. ${ }^{88}$ The EDLC depends on the pore size and surface area of the materials, as well as the electrical conductivity of the electrode. ${ }^{89}$ Therefore, high surface areas are crucial for larger numbers of ions or charge accumulation at the electrode-electrolyte interface, i.e., the higher the specific 
surface area or the micropore volume of the materials the higher the capacitance value (although this relationship is not actively explored in the literature). ${ }^{90}$ Pseudo-capacitive mechanisms depend on charge storage involving fast surface redox reactions, which consist mainly of surface electron transfer by the intercalation or adsorption of charge-compensating ions. ${ }^{91,92}$ Therefore, high surface areas as well as redox-active moieties (e.g., carbonyl compounds) are desirable to benefit pseudo-capacitive mechanisms.

The key advantages of porous pPIs are their tuneable molecular structure, e.g. redox-active groups can be introduced within the backbone, allowing manipulation of beneficial properties for electrochemical applications. ${ }^{87,93}$ Highly crosslinked porous pPI networks possess the above properties and create actives sites for charge or ions to be stored within the porous surface. In addition, pPIs (as part of the broader class of porous organic polymers) are presented as environmentally friendly, low safety risk (with respect to toxicity) and low cost electrodes when compared with metal-containing electrode counterparts. $^{70}$ Specifically, the major advantage is the presence of carbonyl groups in the polyimide framework structure, which provides redox stability and multi-electron transfer capabilities (see Fig. 5). ${ }^{36,70}$

One major drawback for using porous organic polymers (POPs) as electrode materials is poor bulk conductivity, limiting their effectiveness in electrochemical applications. ${ }^{90}$ To overcome this challenge, materials can be carbonised, or conductive additives incorporated into the bulk (e.g. carbon nanotubes, graphene or reduced graphene oxide). ${ }^{43,77,90,94}$ pPIs containing aromatic linkers L3-5 have demonstrated semiconductive properties without the need for additives; however, they can only transfer two electrons in the reversible charge/discharge process as shown in Fig. $5 .^{70}$ In an initial study, Song et al. employed non-crosslinked linear PIs for redox-active systems (from anhydrides L3-4 and various diamines). However, dissolution in the electrolyte during cycling resulted in inefficiency as well as degradation of the PI. ${ }^{95,96}$ To over-

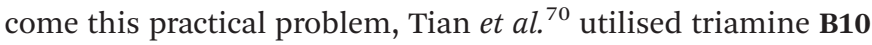
with anhydrides L3-5 to form crosslinked pPIs as electrode materials (cathodes) for Li-ions batteries (LIBs). The highly crosslinked networks were able to sustain harsh chemical and thermal environments without degradation/dissolution. These naphthalene- and perylene-based pPIs utilise carbonyl groups within the structure to effectively conjugate with the aromatic rings as well as ionically bonding to Li ions. The aromatic carbonyl-derived pPIs show high capacity and high cycling stabilities, with those incorporating the perylene linker $\mathbf{L} 5$ giving the best electrochemical performance, around 74\% retention of discharge capacity $\left(57.9 \mathrm{~mA} \mathrm{~h} \mathrm{^{-1 }}\right)$ after 65 cycles. A further approach is detailed by Lv et al. ${ }^{73}$ utilizing $\mathbf{B} 3$ and $\mathbf{L 4}$ to form cathodes that are able to exhibit intramolecular charge transfer with lithium anodes to form solar-to-electrochemical energy storage and conversion devices. Finally, Zhao et al. $^{77}$ reported atomic-layer modification of pPI COFs used as a cathode material for LIBs. They used a mechanical exfoliation method to create atomic-layered or nano-sheet pPIs (thickness ca. $2.6 \mathrm{~nm}$ ) to improve the electrochemical performance (with respect to the bulk material). The dual active site modified atomic-layered pPIs shows initial capacity of $110 \mathrm{~mA} \mathrm{~h} \mathrm{~g}$ (unmodified pPI $25 \mathrm{~mA} \mathrm{~h} \mathrm{~g}^{-1}$ ) with $87.3 \%$ retention after 500 cycles.

Li et $a{ }^{36}{ }^{36}$ reported polycondensation of melamine (B1) with the benzene (L3) and naphthalene (L4) linkers to generate pPIs for anode materials for $\mathrm{Na}$ ion batteries. When compared to graphitic carbon (used as anodic materials in both $\mathrm{Na}$ and $\mathrm{Li}$ ion batteries), ${ }^{97}$ these pPI networks facilitate higher mobility of the larger sized $\mathrm{Na}$ ions (owing to increased pore size relative to graphitic carbon). These materials thus performed more effectively as anodes, possessing more reactive sites for electrode-electrolyte interactions and ion transport during the reversible sodiation/desodiation processes. Furthermore, the randomly arranged conjugated systems and larger conjugated units provided higher stability and conductivity than the graphitic carbon. The discharge capacity of PI-1 (using linker L4) and PI-2 (using linker L3) are 330.8 and $137.02 \mathrm{~mA} \mathrm{~h} \mathrm{~g}{ }^{-1}$, respectively, at $100 \mathrm{~mA} \mathrm{~g}^{-1}$ after 20 cycles, when compared with the discharge capacity of graphitic carbon at $31 \mathrm{~mA} \mathrm{~h} \mathrm{~g}^{-1}$ (see Fig. 6). The higher redox activity and conductivity of PI-1 can be attributed to the higher electron affinity values and the ionisation potential and lower HOMO-LUMO gap as compared to PI-2 (L3 linker). Effectively, PI-1 is more conjugated than PI-2. The long-term stability of PI-1 and PI-2 are shown in Fig. 6, with minimal capacity degeneration ( $c a$. 10\% for PI-1) even after 1000 cycles.
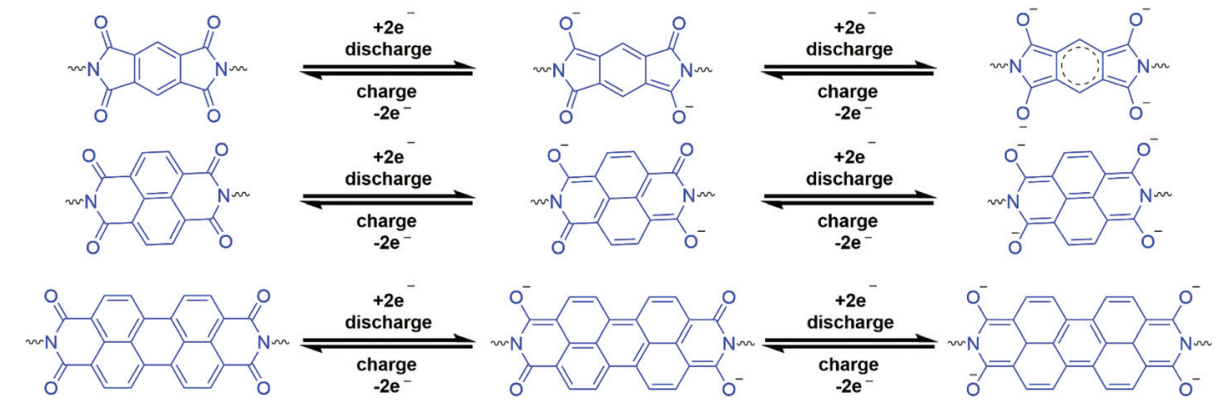

Fig. 5 Various oxidation states of common anhydride linkers $L 3-5{ }^{70}$ 


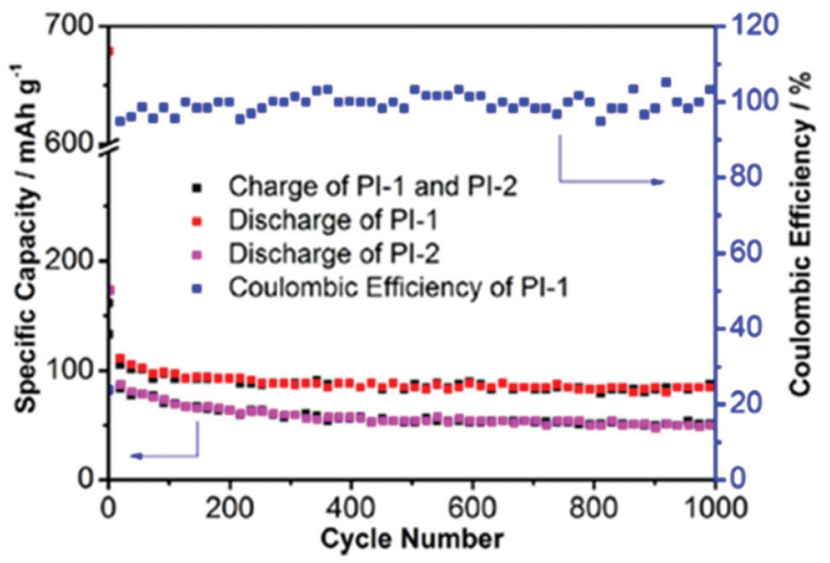

Fig. 6 Long-term cycling performance of PI-1 (B1 and L4) and PI-2 (B1 and L3) at $5 \mathrm{~A} \mathrm{~g} \mathrm{~g}^{-1}$, image reproduced with permission. ${ }^{36}$ Copyright Elsevier 2016.

Roy et $a .^{23}$ condensed dicarboxylic acids M1-3 (containing diimides) with tetra-amines C5-6 to form polybenzimidazole rings within pPI networks for use as electrode materials for energy storage applications. The incorporation of the polybenzimidazole units (present in M1-3) in the pPIs provides dynamic dipolar interactions between the electrolyte cations (1 $\mathrm{M} \mathrm{H}_{3} \mathrm{PO}_{4}$ ) and the pPI pore walls, facilitating proton storage on the pore walls during the charge-discharge process. In addition, the extended $\pi$-conjugation and presence of heteroatoms throughout the pPI networks provide conductivity and enhance the redox activity of the network. The specific capacitance of networks formed from the tetraamine core $\mathbf{C 4}$ and linker L3 (BIBDZ), L4 (NIBDZ) and L5 (PIBDZ) were 88.4, 66.56 and $5.65 \mathrm{~F} \mathrm{~g}^{-1}$, respectively, at $5 \mathrm{~A} \mathrm{~g}^{-1}$. The higher capacitance value of $\mathbf{L} 3$ was attributed to the higher surface area (accommodating larger number of interactions between the electrode-electrolyte interface, assisting EDLC) when compared to L4 and L5, overriding the increased units available for $\pi$-conjugation of the other pPIs. Most recently, Royuela et al. ${ }^{76}$ reported a crystalline pPI NDI-COF (synthesised from $\mathbf{L} 4$ and B10), as an electrocatalyst in the oxygen reduction reaction (ORR). The majority of known ORR catalysts rely on containing metals within their structure, or pyrolysis or addition of conductive materials to achieve conductivity. ${ }^{98-100}$ The NDI-COF for ORR represents one of the first metal-free catalysts in this field that doesn't rely upon pyrolysis or additives. Owing to the increased electroactive area of the NDI-COF $v s$. the bare glassy carbon electrode, the capacitance current increases upon addition of the pPI, as shown by cyclic voltammetry. It is noteworthy that pPI networks are largely unexplored in the field of electrocatalysis and electrocatalytic behaviour.

\section{Applications}

\subsection{Gas storage and separation}

The high surface areas, high stabilities preventing degradation (as discussed in the previous section), alongside their syn- thetic simplicity and tunability (including starting materials, chemical make-up, porosity), make pPIs attractive candidates for gas capture in harsh environments. The literature focuses on $\mathrm{CO}_{2}, \mathrm{H}_{2}, \mathrm{C}_{6} \mathrm{H}_{6}, \mathrm{CH}_{4}$ and $\mathrm{CH}_{3} \mathrm{OH}$ (water is considered in a separate section in this review, see section 4.1.2), and are discussed below:

4.1.1. Carbon dioxide $\left(\mathrm{CO}_{2}\right)$ capture and storage. Crosslinked pPI 3D networks have been widely used for the adsorption and storage of various gases. Porous polyimides are promising for $\mathrm{CO}_{2}$ capture owing to their compatible pore size with the kinetic diameter of $\mathrm{CO}_{2}(0.33 \mathrm{~nm})$, easy tuneable chemical functionality and ability to combine different properties. The reported $\mathrm{CO}_{2}$ uptake by pPIs is summarised in Table 3.

The major factors responsible for high $\mathrm{CO}_{2}$ uptakes in pPIs are not (solely) reliant on high specific surface areas; for example, the pPIs synthesised by Rao et al. ${ }^{38}$ possess a surface area of $2213 \mathrm{~m}^{2} \mathrm{~g}^{-1}$ (Td-PPI, synthesised from $\mathbf{C} 1$ and $\mathbf{L 5}$ ) and $\mathrm{CO}_{2}$ uptake of $31 \mathrm{wt} \%$, while Tr-PPI, synthesised from $\mathbf{B} 3$ and $\mathbf{L 5}$, has as surface are of $400 \mathrm{~m}^{2} \mathrm{~g}^{-1}$ and uptake of $45 \mathrm{wt} \%$ (both measured at $195 \mathrm{~K}$ and $1 \mathrm{bar}$ ). Direct comparison of the reported pPIs surface areas with $\mathrm{CO}_{2}$ uptake efficiency is challenging, as the conditions for $\mathrm{CO}_{2}$ uptake vary greatly between each experiment with little standardisation evident across the studies surveyed in this review. For example, the pPIs synthesised by Roy et al. $^{23}$ (NIBDZ from $\mathbf{C 6}$ and the dianhydride M2) has a low surface area $\left(118 \mathrm{~m}^{2} \mathrm{~g}^{-1}\right)$ but fair $\mathrm{CO}_{2}$ uptake (14.56 wt\%). In contrast, the pPIs synthesised by Li et al. ${ }^{19}$ has far higher surface areas, by a factor of up to 10 (e.g. MPI-1, $1454 \mathrm{~m}^{2} \mathrm{~g}^{-1}$ synthesised from $\mathbf{C 1}$ and L3) but this significant increase is not reflected in an increase in $\mathrm{CO}_{2}$ uptake, with similar values of $10-16 \mathrm{wt} \% \mathrm{CO}_{2}$ uptake. However NIBDZ measurements were recorded at a far lower temperature (195 K) than that of MPI-1 (273 K), highlighting the discrepancies mentioned previously. ${ }^{19}$

More important than high surface areas are pPIs with high specific surface areas that contain high concentrations of micropores $(<2 \mathrm{~nm})$ or ultramicropores $(<0.7 \mathrm{~nm})$, and ideally without high mesopore $(2-50 \mathrm{~nm})$ volumes that will absorb competitive gas species and potentially block the pores. ${ }^{101}$ The smaller volumes are more compatible with the kinetic diameter of $\mathrm{CO}_{2}$. As an example, Luo et al. ${ }^{45}$ synthesised PI1-3 with mesoporous volumes and poorer $\mathrm{CO}_{2}$ uptakes $(7.3 \mathrm{wt} \%$ for $660 \mathrm{~m}^{2} \mathrm{~g}^{-1}$ surface area), whereas pPIs with similar surface areas (e.g. Shi et al., ${ }^{52}$ PPBPI-PENA-CR, $633 \mathrm{~m}^{2} \mathrm{~g}^{-1}$ ) but with higher overall pore volume and microporous volume exhibited higher $\mathrm{CO}_{2}$ uptake (10.43 wt\%). A further example is found in the linear based PIs from $\mathbf{L 7}$ and $\mathbf{A 6}$ by Wu et al. ${ }^{55}$ Once formed and carbonised with ZIF aerogels the composites formed structures with pore sizes matching that of the kinetic diameter of $\mathrm{CO}_{2}$, giving an increased $\mathrm{CO}_{2}$ capture capacity of $9.81 \mathrm{wt} \%$ at $298 \mathrm{~K}$ when compared to non-carbonised, though overall still low (however these linear polymers and the effect of $\mathrm{ZIF}$ on $\mathrm{CO}_{2}$ uptakes are not investigated individually in this paper). It is important to note that if the pPIs have only ultramicropores, the $\mathrm{CO}_{2}$ present may block the pores and so stop further uptake of $\mathrm{CO}_{2} \cdot{ }^{101}$ 
Table 4 Gas uptakes from reported pPIs where $\mathrm{H}_{2}=$ hydrogen, $\mathrm{H}_{2} \mathrm{O}=$ water vapor, $\mathrm{CH}_{4}=$ methane $\mathrm{C}_{6} \mathrm{H}_{6}=$ benzene, $\mathrm{C}_{6} \mathrm{H}_{12}=$ cyclohexane, $\mathrm{A}=$ amorphous; $\mathrm{C}=$ crystalline; i = at $77 \mathrm{~K}, 1$ bar; ii = at $195 \mathrm{~K}, 1$ bar; iii = at $273 \mathrm{~K}, 1$ bar, iv $=298 \mathrm{~K}, 1$ bar, v = $77 \mathrm{~K}, 30$ bar, * wt\% values were converted for the purpose of this review from published isotherms using the conversion formula wt $\%=\left(\mathrm{mmol} \mathrm{g}^{-1} \times 100 \times \mathrm{mol}\right.$ weight $) / 1000$ where mmol $\mathrm{g}^{-1}$ $=\left(\mathrm{cm}^{3} \mathrm{~g}^{-1}\right) / 22.414 \mathrm{~cm}^{3} \mathrm{mmol}^{-1}$

\begin{tabular}{|c|c|c|c|c|c|c|}
\hline Name in paper & $\mathrm{H}_{2}(\mathrm{wt} \%)$ & $\mathrm{H}_{2} \mathrm{O}(\mathrm{wt} \%)$ & $\mathrm{CH}_{4}(\mathrm{wt} \%)$ & $\mathrm{C}_{6} \mathrm{H}_{6}(\mathrm{wt} \%)$ & $\mathrm{C}_{6} \mathrm{H}_{12}(\mathrm{wt} \%)$ & Ref. \\
\hline NPI-1 & - & $14.1^{\text {iv }}$ & $1.35^{\mathrm{iii}}$ & $90.5^{\mathrm{iv}}$ & $58.1^{\mathrm{iv}}$ & 34 \\
\hline NPI-2 & - & $9.5^{\mathrm{iv}}$ & $0.78^{\mathrm{iii}}$ & $41.5^{\mathrm{iv}}$ & $17.9^{\text {iv }}$ & 34 \\
\hline NPI-3 & - & $10.2^{\mathrm{iv}}$ & $1.07^{\mathrm{iii}}$ & $59.9^{\text {iv }}$ & $37.4^{\mathrm{iv}}$ & 34 \\
\hline MPI-1 & - & $16.7^{\mathrm{iv}}$ & - & $119.8^{\mathrm{iv}}$ & $54.1^{\mathrm{iv}}$ & 19 \\
\hline MPI-2 & - & $9.9^{\mathrm{iv}}$ & - & $76.6^{\text {iv }}$ & $44.8^{\mathrm{iv}}$ & 19 \\
\hline MPI-3 & - & $9.6^{\mathrm{iv}}$ & - & $54.9^{\text {iv }}$ & $41.5^{\mathrm{iv}}$ & 19 \\
\hline PI-1 & $0.66^{\mathrm{i}}$ & - & - & - & - & 45 \\
\hline PI-2 & 0.23 & - & - & - & - & 45 \\
\hline PI-3 & 0.58 & - & - & - & - & 45 \\
\hline BIBDZ & $0.75^{i_{*}}$ & - & $0.79^{\mathrm{iv} *}$ & - & - & 23 \\
\hline PPBPI-1-Cr & - & - & $1^{\mathrm{iii} *}$ & - & - & 18 \\
\hline PPBPI-2-CR & - & - & $1^{\mathrm{iii} *}$ & - & - & 18 \\
\hline PPBPI-H-CR & - & - & $0.62^{\mathrm{iii} *}$ & - & - & 22 \\
\hline PPBPI_Fe-CR & - & - & 0.24 & - & - & 22 \\
\hline PPBPI-Mn-CR & - & - & 0.37 & - & - & 22 \\
\hline PPBPI-PA-CR & - & NA & $0.6^{\mathrm{iii} *}$ & - & - & 52 \\
\hline PPBPI-PEPA-CR & - & NA & 1.1 & - & - & 52 \\
\hline PPBPI-PENA-CR & - & $19.27^{\mathrm{iv} *}$ & 1.1 & - & - & 52 \\
\hline PI-1 & $0.7^{i_{*}}$ & - & $0.5^{\mathrm{iii} *}$ & - & - & 70 \\
\hline PI-0\%6FAPB & - & 383.8 & - & - & - & 79 \\
\hline PI-25\%6FAPB & - & 12.5 & - & - & - & 79 \\
\hline PI-37.5\%6FAPB & - & 9.8 & - & - & - & 79 \\
\hline PI-50\%6FAPB & - & 9.5 & - & - & - & 79 \\
\hline MPI-6FA & - & $8.5^{\mathrm{iv}}$ & $1.42^{\mathrm{iv} *}$ & $80.9^{\mathrm{iv}}$ & $44^{\text {iv }}$ & 48 \\
\hline API-6FA & - & - & 1.07 & - & - & 48 \\
\hline MPI-BTA & - & 10.4 & 1.07 & 72.8 & 40.4 & 48 \\
\hline MPI-BPA & - & 13.3 & 0.78 & 104.9 & 60.2 & 48 \\
\hline PI & $1.217^{\mathrm{i}}$ & $30^{\mathrm{iv}}$ & - & $99.2^{\text {iv }}$ & $59.7^{\text {iv }}$ & 85 \\
\hline PI-1 & $3.2^{\mathrm{i}}$ & - & - & - & - & 81 \\
\hline PI-2 & 2.6 & - & - & - & - & 81 \\
\hline SPI-A-H & - & - & 0.62 & - & - & 67 \\
\hline SPI_M-H & - & - & 0.6 & - & - & 67 \\
\hline SPI-A-B & - & - & 0.56 & - & - & 67 \\
\hline sPI-m-B & - & - & 0.49 & - & - & 67 \\
\hline MPI & - & - & $0.92^{\mathrm{iii}}$ & - & - & 69 \\
\hline MPI-S & - & - & 0.59 & - & - & 69 \\
\hline MPI-Ag & - & - & 0.53 & - & - & 69 \\
\hline
\end{tabular}

The isosteric heat of adsorption $\left(Q_{\mathrm{st}}\right)$ provides a general measure of the interactions of gases and porous structures, measuring the heat produced when a gaseous molecule is physiosorbed onto the polymeric surface. Higher $Q_{\text {st }}$ means better interactions and higher absorbance values, though values over $50 \mathrm{~kJ} \mathrm{~mol}{ }^{-1}$ typically indicate chemisorption. ${ }^{102,103}$ Specifically, the interaction of $\mathrm{CO}_{2}$ and the pore walls in $\mathrm{CO}_{2}^{-}$ pPI gas uptake studies is of interest here (see Table 4). The strength of the interactions can be tuned in pPIs via chemical modification of the starting monomers. As an example, NPI-3 (B10 and L4) synthesised by Li et al. ${ }^{34}$ has similar $\mathrm{CO}_{2}$ uptake to NPI-1 (C1 and L4) as it has similar $Q_{\mathrm{st}}$, despite having far lower surface area (see Table 3). A method of affecting the heat of absorption, as a gauge of the strength of $\mathrm{CO}_{2}$ interactions with the pore walls, is found by the incorporation of heteroatoms or polar groups into the pPIs. Incorporation of heteroatoms and polar groups affects the interactions between the $\mathrm{CO}_{2}$ and the pore wall via dipole-quadruple interactions, H-bonding or Lewis acid-base interactions. As an example, the pPI Tr-PPI (B3 triamine) synthesised by Rao et al. ${ }^{38}$ has a higher $\mathrm{N}$ content per repeat unit than the Td-PPI (C1 tetraamine) and therefore, despite having a far lower surface area, has a higher $\mathrm{CO}_{2}$ uptake of $45 \mathrm{wt} \%$ vs. $31 \mathrm{wt} \%$ (please note: both these measurements were performed at $195 \mathrm{~K}$ and $1 \mathrm{bar}$ ).

It is noted that pPIs synthesised by Hossain et al. ${ }^{46}$ from A5 and L12 and crosslinked with PEG units are not examined in regard to surface area or $\mathrm{CO}_{2}$ uptake, but showed promise in $\mathrm{CO}_{2}$-selective permeability.

4.1.2. Uptake of other compounds (gas and vapor). In addition to $\mathrm{CO}_{2}$, the uptake of several other volatile organic gas species by pPI crosslinked networks are reported in Tables 4 and 5. The most common of these are hydrogen, water, methane, benzene, and a range of other aliphatic and cycloalkanes and alkenes.

The efficient absorbance and storage of hydrogen gas is important for future fuel applications and a move to net zero emissions. ${ }^{104-106}$ The pPIs reported in Table 4 show hydrogen gas uptake of up to $3 \mathrm{wt} \%$ at $77 \mathrm{~K}$ and 1 bar, which is low when compared with the published data from high performing MOFs (e.g. Furukawa et al.'s MOF-210, $17.6 \mathrm{wt} \%$ at $77 \mathrm{~K}$ and 80 
Table 5 Aliphatic VOC absorption by reported pPIs where A: amorphous; C: crystalline; i: at 77 K, 1 bar; ii: at 195 K, 1 bar; iii: at 273 K, 1 bar, iv: 298 K, 1 bar, v: 77 K, 30 bar

\begin{tabular}{|c|c|c|c|c|c|c|c|c|}
\hline Name in paper & $\mathrm{C}_{2} \mathrm{H}_{6}(\mathrm{wt} \%)$ & $\mathrm{C}_{2} \mathrm{H}_{4}(\mathrm{wt} \%)$ & $\mathrm{C}_{3} \mathrm{H}_{8}(\mathrm{wt} \%)$ & $\mathrm{C}_{3} \mathrm{H}_{6}(\mathrm{wt} \%)$ & $\mathrm{C}_{4} \mathrm{H}_{10}(\mathrm{wt} \%)$ & $\mathrm{C}_{4} \mathrm{H}_{8}(\mathrm{wt} \%)$ & $\mathrm{C}_{4} \mathrm{H}_{6}(\mathrm{wt} \%)$ & Ref. \\
\hline SPI_M-H & $4.47^{\mathrm{iv}}$ & - & $8.44^{\text {iv }}$ & $10.50^{\mathrm{iv}}$ & $17.80^{\mathrm{iv}}$ & $19.60^{\mathrm{iv}}$ & $25.86^{\text {iv }}$ & 67 \\
\hline sPI-m-B & $3.72^{\mathrm{iv}}$ & $-\ldots$ & $7.61^{\mathrm{iv}}$ & $9.70^{\mathrm{iv}}$ & $12.52^{\mathrm{iv}}$ & $12.99^{\mathrm{iv}}$ & $18.30^{\mathrm{iv}}$ & 67 \\
\hline MPI & $4.02^{\mathrm{iii}}$ & $4.35^{\mathrm{iii}}$ & - & - & - & - & - & 69 \\
\hline MPI-S & $4.16^{\mathrm{iii}}$ & $4.68^{\mathrm{iii}}$ & - & - & - & - & - & 69 \\
\hline MPI-Ag & $4.17^{\mathrm{iii}}$ & $4.96_{\ldots}^{\mathrm{iii}}$ & - & - & - & - & - & 69 \\
\hline
\end{tabular}

bar, although these frameworks rely on potentially scarce metal centres, e.g. zinc). ${ }^{107-109}$ With respect to pPIs, the best uptake was demonstrated by Wang et al. ${ }^{81}$ with the tetrahedral core $\mathbf{C} 1$ and dianhydrides L3 (PI-1) and L4 (PI-2). These two pPIs possess large surface areas $\left(1407 \mathrm{~m}^{2} \mathrm{~g}^{-1}\right.$ and $732 \mathrm{~m}^{2} \mathrm{~g}^{-1}$, respectively) with a higher ultramicroporous pore volume. These ultramicropores are compatible in size with the kinetic diameter of hydrogen (of $0.29 \mathrm{~nm}$ ), which facilitates increased hydrogen uptake. The authors found that increased $\pi$-electron delocalisation groups present in the aromatic linker $\mathbf{L} 4$ (when compared to L3) aided $Q_{\text {st }}$ values at a range of hydrogen $w \mathrm{t} \%$ uptakes (0.5-1 wt\%) and hence overall hydrogen uptake. Despite the importance of $\mathrm{H}_{2}$ uptake and storage, this remains a largely unexplored area of application for pPIs.

Water sorption and harvesting will be an important future application for future proofing water resources, especially in arid environments. The crosslinked conjugated pPIs synthesised by Qiao et al. ${ }^{79}$ demonstrate the highest water sorption at $383.8 \mathrm{wt} \%$ (Table 4). This high uptake is attributed to the synthetic conditions employed, forming aerogels from A6, A14 and $\mathbf{L} 7$ owing to the slow reactions at ambient conditions, and slow introduction of crosslinking agent B8. However, the exact mechanism of water uptake was not fully explored in this study, leading to interesting avenues for research into future water-harvesting applications of pPIs, potentially fully tuneable by controlling aerogel formation (in addition to controlling chemical content).

High water uptake in other studies are attributed to either the introduction of heteroatoms, especially oxygen-containing linkers such as ester A6 and ketone L13 (see Qiao et al. ${ }^{79}$ and Li et $a l .{ }^{48}$ ), or a decrease in (hydrophobic) aromaticity of the formed pPI by Shen et al. ${ }^{85}$ Those pPIs synthesised from the hydrophobic monomers $\mathbf{L 4}$ and $\mathbf{L 5}$ show low water uptakes. $^{34,48,52}$ In the case of the materials with the largest water uptake, ${ }^{79}$ the introduction of the hydrophobic $\mathrm{CF}_{3}$-containing monomer A14 into the formed pPI aerogels leads to dramatically decreased water absorption capabilities (from 383.8 to $9.5 \mathrm{wt} \%$ when the $\mathrm{CF}_{3}$-containing monomer $\mathbf{A 1 4}$ content is increased to $50 \mathrm{~mol} \%$ ).

Volatile organic compound (VOC) sorption by pPIs can be separated into two specific focus areas: cyclic (benzene and cyclohexane) and aliphatic hydrocarbon adsorption. In the case of the cyclic hydrocarbons, Li et al. ${ }^{34,48,86}$ synthesised several pPIs based on naphthalene $\mathbf{L 4}$ and pyromellitic (a single benzene ring linker) L3 anhydrides for successful absorption of cyclic VOCs. With respect to benzene absorption, it was found that the more aromatic the skeleton the higher the benzene absorption (owing to $\pi$-interactions). Differences between the individual pPIs in benzene uptake were attributed to differences in surface areas, with lower surface areas leading to lower benzene uptake. ${ }^{85}$ The same pPIs were also used for cyclohexane sorption, though absorbing significantly less ( $c a$. 40\% lower uptake when compared with benzene) due to the lack of $\pi$-interactions. ${ }^{34,85,86}$ The increased absorption of cyclohexane by the pPI synthesised by Shen et al. ${ }^{85}$ from $\mathbf{C 4}$ and $\mathbf{L} \mathbf{3}$ was due to the cycloaliphatic core used - maximizing aliphatic-aliphatic interactions.

For the case of aliphatic hydrocarbon uptake, methane absorption was reported for a large number of papers (Table 5); however, the recorded absorbed weight percentages were never higher than $1.42 \mathrm{wt} \%$ (Li et al. ${ }^{48}$ ). This low absorption is theorised to be a result of poor interactions with the pPIs and incompatible kinetic diameters of the $\mathrm{CH}_{4}(0.38 \mathrm{~nm})$ and pPI pore volumes. ${ }^{18,22,23,34,48,50,67,69,70}$ In regards to absorbance of other aliphatic VOCs (alkanes and alkenes), this review only found two papers by Yan et al. ${ }^{69,110}$ that addressed this specific application: a Ag-doped pPI MPI-Ag (from C1 and L3) and its four non-doped pPI counterparts SPI-A-H (C1 and L1), sPI-M-H (C4 and L1), sPI-A-B (C1 and L2) and SPI-M-B (C4 and L2). Interestingly, the pPIs reported were predominantly non-conjugated, which aided interaction with the aliphatic VOCs and their sorption. In parallel to cyclic VOC (benzene and cyclohexane) sorption studies, the pPIs MPI, MPI-S, and MPI-Ag (from C1 and L3) were able to adsorb unsaturated aliphatic VOCs when $\mathrm{Ag}$ was present in the pPI owing to $\mathrm{C}=\mathrm{C}$ bond and $\mathrm{Ag}^{+} \mathrm{d}$-orbital overlap interactions $\left(\pi-\mathrm{Ag}^{+}\right)$. In contrast, the pPI without $\mathrm{Ag}^{+}$units were better suited to adsorb saturated aliphatic VOCs, although the reasons behind this observation were not explored in the study. Further studies by Jiang et al. ${ }^{71}$ show selective adsorption of acetylene from ethylene/ acetylene mixtures due to $Q_{\text {st }}$ values clearly demonstrating a greater affinity of the material for acetylene (up to $9.0 \mathrm{wt} \%$ uptake).

We found several reports of nitrogen sorption, rather than just related to surface area calculations. However, in the majority of cases the level of $\mathrm{N}_{2}$ gas absorbed was extremely 
low: in the cases where these values are calculated and reported, or from our own calculations taken from isotherms provided, the values never exceeded $1 \mathrm{wt} \%$, with the majority below 0.2 wt $\%$.

\subsection{Heterogeneous catalysis}

Porous organic polymers play an important role in modern catalytic applications. ${ }^{111,112}$ In this context, pPI networks can be applied either by incorporating the active site within the polymeric structure (as pendant group or incorporated into one of the monomers), or by directly exploiting the activity and properties of conjugated pPIs. Nevertheless, application of pPI networks in catalysis has been, thus far, limited to a few examples as discussed below.

In a first application of polyimides in catalysis, Shultz et $a .^{21}$ prepared a metalloporphyrin ring functionalised with aromatic moieties (L20), two of which bore anhydride functionalities that could be used for the condensation reaction with tetramine $\mathbf{C 1}$. This reaction generated a polyimide network that was subsequently metalated at the porphyrin rings with iron(II) or manganese(II). The synthesised polyimide performed as recyclable catalyst for the epoxidation of styrene using iodosylbenzene as the oxidant; however, the recyclability was only partially effective as most of the catalytic activity was lost after three reaction cycles. Considering the excellent catalytic activity of Lewis acidic centres in metalloporphyrins for the cycloaddition of $\mathrm{CO}_{2}$ to epoxides, ${ }^{113,114}$ it is expected that appropriately designed and constructed pPI catalysts would perform well in this reaction; ${ }^{115,116}$ to the best of our knowledge, these promising materials have not yet been explored for this specific application.

A different catalytic application was reported by Chu et al. ${ }^{27}$ in the search of organic photocatalysts for hydrogen generation. To this aim, a crystalline pPI network was fabricated from the thermal reaction of melamine (B1) and pyromellitic dianhydride (L3) at $325{ }^{\circ} \mathrm{C}$. The good crystallinity of the polymer was attributed to the solvent-free, high-temperature synthesis that led to the initial precipitation of crystals of oligomeric pPI. Whereas the individual monomers were colourless, the produced pPI network displayed a yellow color due to the extended $\pi$-conjugation. The pPI displayed attractive optoelectronic properties with a bandgap of $2.7 \mathrm{eV}$ and a spatially separated HOMO (on the melamine moiety) and LUMO (on the pyromellitic moiety), potentially favouring charge separation during photocatalytic processes. The performance of the catalyst in the $\mathrm{H}_{2}$ evolution reaction (HER) was tested in the presence of methanol as sacrificial reagent and using Pt as cocatalyst under visible light irradiation; $70 \mathrm{mmol}$ of $\mathrm{H}_{2}$ was produced after $10 \mathrm{~h}$ of irradiation. The authors compared the photocatalytic activity of the pPI with that of graphitic carbon nitride $\left(\mathrm{g}-\mathrm{C}_{3} \mathrm{~N}_{4}\right)$ finding that, the two materials displayed similar photocatalytic performance despite the pPI possessing half the surface area of $\mathrm{g}-\mathrm{C}_{3} \mathrm{~N}_{4}$. Interestingly, the crystallinity of the pPI was found to play an important role: in a control experiment with a non-crystalline analogue of the pPI no photocatalytic activity was detected. In a subsequent study
Chu et $a .^{26}$ attempted to achieve bandgap modulation and optimize catalytic activity for the pPIs by varying the degree of polymerisation by using different temperatures (in the range from 250-350 ${ }^{\circ} \mathrm{C}$ ) during syntheses using the same starting monomers B1 and L3 as in the previous example. The increase of the polymerisation temperature above $250{ }^{\circ} \mathrm{C}$ had a clear positive effect on crystallinity and on the degree of polymerisation; the UV-Vis optical absorption edge was progressively bathochromically shifted by increasing the polymerisation temperature, with the bandgaps decreasing from $3.39 \mathrm{eV}$ (polymer prepared at $250{ }^{\circ} \mathrm{C}$ ) to a more application-relevant value of $2.56 \mathrm{eV}$ for the polymer prepared at $350{ }^{\circ} \mathrm{C}$. The latter effect was attributed to achieving stronger orbital overlap by increasing the degree of polymerisation. DFT calculations supported this observation as the bandgap of oligomeric pPIs was found to decrease with chain length. ${ }^{117}$ When pPIs produced at different temperatures were tested in hydrogen generation, it was found that the materials produced at intermediate temperatures performed better. Specifically, the material produced at $300{ }^{\circ} \mathrm{C}$ was the best catalyst under full arc light whereas that produced at $325{ }^{\circ} \mathrm{C}$ was the best photocatalyst under visible light irradiation. This effect was attributed to the balance of several factors contributing to or affecting the photocatalytic activity. Indeed, despite a higher degree of polymerisation, the pPI prepared at the highest temperatures suffered from strong particle aggregation (with consequent decrease of surface area) and decreased redox power. Overall, this investigation highlighted a promising route worthy of further exploration, showing that the reaction conditions, and thus the degree of polymerisation of pPIs, can be used to engineer and modulate the bandgap of polymeric photocatalysts.

Kim et al. ${ }^{32}$ synthesised pPI networks from the triamine B10, anhydride L3 and the mono amine D1, (yielding MPI-Phen), showing catalytic activity in the Suzuki reactions. These pPI networks were synthesised both on and without a melamine sponge support, allowing ease of handling under catalytic conditions, placing in or removal from reaction vessels, whilst still allowing access to high surface areas $\left(723 \mathrm{~m}^{2} \mathrm{~g}^{-1}\right.$ without the sponge and $524 \mathrm{~m}^{2} \mathrm{~g}^{-1}$ on the sponge support). The catalytic activity of the networks was observed upon coordination of $\mathrm{Pd}$ (II) ions to the mono amine D1, and activity evaluated for the Suzuki coupling reaction between bromobenzene and phenylboronic acid in toluene (and other solvents) at $95{ }^{\circ} \mathrm{C}$, to give a maximum yield of $83.3 \%$. The recycling results showed a slight decrease in yields, which could be attributed to the leaching of Pd(II) ions from the network. Zhu et $a .^{72}$ reported porphyrin-based pPI networks synthesised from dianhydride $\mathbf{L} 3$ and $\mathbf{L} 4$ with tetraamine porphyrin C9 monomer (PPPP-1 and PPPP-2, respectively). The major advantage of porphyrin-based pPIs in heterogeneous catalysis applications is found in the large size of the porphyrin linker $(\sim 2 \mathrm{~nm})$, creating large pores inside the framework. Furthermore, catalytically active sites can be modified by binding various metal ions to the porphyrin linker (strong $\pi$-metal orbital coupling also enhances the heterogeneous binding of the ions). The authors also loaded the porphyrin- 


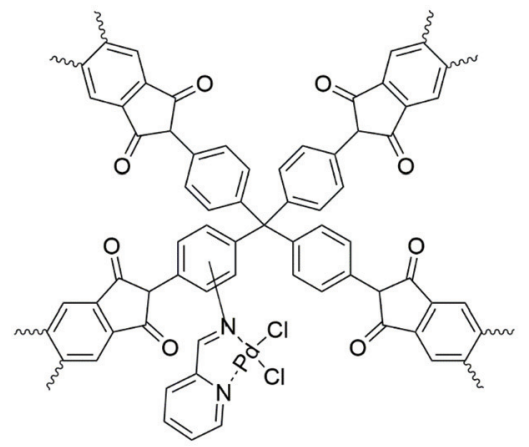

PPI-1-NPy-Pd

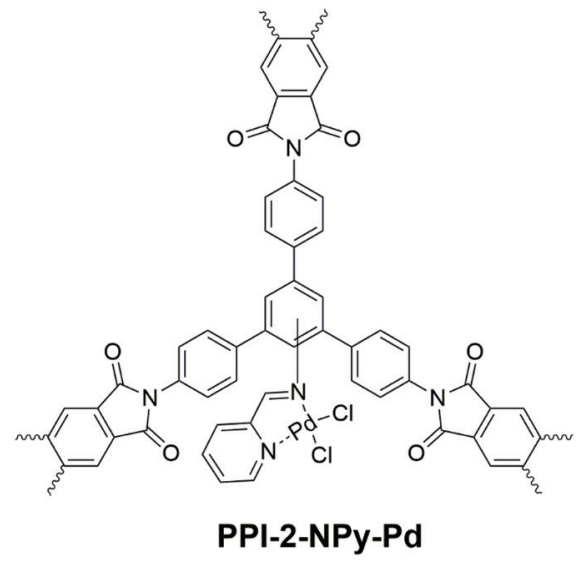

Fig. 7 Schematic representation of heterogeneous Pd catalysts based on porous polyimide networks from Rangel Rangel et al. ${ }^{54}$

based pPI networks with Pd nanoparticles (to form Pd@PPPP-1 and Pd@PPPP-2 from PPPP-1 and PPPP-2 respectively) to catalyse the Suzuki-Miyaura coupling reaction. Pd@PPPP-1 and Pd@PPPP-2 were utilised to catalyse substituted phenylboronic acid and aryl halides to form $\mathrm{C}-\mathrm{C}$ bonds with high catalytic activity and product yield greater than $90 \%$. Furthermore, the pPI catalytic networks were recovered and reused 5 times without any loss of catalytic activity of Pd@PPPP-1 and Pd@PPPP-2.

Rangel Rangel et al. ${ }^{54}$ synthesised 2 different pPI networks with triamine $\mathbf{B 1 0}$ and tetraamine $\mathbf{C 1}$ with dianhydride L3, respectively. The networks were nitrated with $\mathrm{HNO}_{3} / \mathrm{H}_{2} \mathrm{SO}_{4}$ and subsequently reduced with $\mathrm{SnCl}_{2}$ to yield amine-decorated aromatic cores (B10 or C1). These modified networks were then reacted with picolinaldehyde to yield iminopyridine ligands for coordination with palladium (Fig. 7). It is noteworthy that these modifications resulted in a significant decrease in thermal stability of the final network structures (as discussed in section 3.1). The catalytic activity was monitored using the Suzuki coupling reaction of halobenzenes with various aryl boronic acids; when compared to the palladium ligand only (i.e., not bound to the pPI networks) the pPI was found to yield on average twice the efficiency (calculated from GC and GCMS of the Suzuki coupling reaction). The increase in efficiency is related to the hydrophobicity of the pPI and the products from the coupling, as well as increased surface area for contact. Furthermore, the pPIs' excellent catalytic activity in aqueous media provide very useful greener alternatives to other heterogeneous palladium catalyst systems.

\subsection{Other applications}

Four further broad areas of application were found besides those listed above and are detailed below:

4.3.1. Drug delivery. There are several documented porous materials that have been utilised in drug delivery applications, ${ }^{80,118,119}$ however pPIs have been largely ignored in this field. One example found was for the PPIs synthesised by Fang et al. ${ }^{80}$ Here the pore sizes (1.0-1.5 nm) of the pPIs were found to be compatible with the commercially available drugs ibuprofen (of similar size, 0.5-1.0 nm), captopril (utilised for the treatment of hypertension and congestive heart failure) and caffeine. Controlled release over a 6-day period was demonstrated, with up to $95 \%$ release recorded for ibuprofen. Significant opportunities exist for further exploration of this field of study.

4.3.2. Removal of organic pollutants from aqueous environment. Several pPIs have been utilised for the removal of organic small molecules from aqueous systems. Fang et al. ${ }^{9}$ synthesised pPIs capable of absorbing Rhodamine B (up to $17 \mathrm{wt} \%$, determined by TGA). The dye could be recovered from the networks by washing with methanol. The absorbance of the Rhodamine $\mathrm{B}$ excitation peak bound in the network in aqueous environments decreased linearly in dependence of temperature, showing promise for temperature sensing devices; however, the mechanisms behind the quenching were not explored in this study.

Wang et al. ${ }^{28}$ used a pPI synthesised from B1 and L3 to investigate the removal of organic pollutants (the dye methyl orange and the antibiotic tetracycline) from aqueous solutions. Removal was monitored by UV/Vis spectroscopy and further investigated with IR spectroscopy to show how the amino groups of the pPI could interact ionically with the sulfonic groups of methyl orange, leading to adsorption. These pPIs absorbed methyl orange and tetracycline at 555.6 and $122.2 \mathrm{mg} \mathrm{g}^{-1}$, respectively, at $298 \mathrm{~K}$ from aqueous solutions.

A further good example of the potential of crosslinked pPIs for the removal of undesired species from aqueous systems is found in the study by Simón-Herrero et al. ${ }^{29}$ Here linear polyimides from $\mathbf{L 7}$ and $\mathbf{A 6}$ with hydrophobic properties were used to separate oil from water (please note: the crosslinked pPI formed via addition of $\mathbf{B} 3$ was not studied in this investigation, despite the potential for separation enhancement). In contrast, Qiao et al. ${ }^{79}$ reported on high surface area $\mathrm{CF}_{3}$-functionalised pPI-based aerogels with high water repulsion for the adsorption of organic species from aqueous systems. The pPI aerogels removed both chloroform and toluene from aqueous mixtures. However, the investigation only reported empirical observations, with no quantification of the performance of the 
materials presented. Although a range of other $\mathrm{CF}_{3}$-containing water-repellent pPIs have been synthesised, ${ }^{16,18,22,50,52,60,61}$ they have not been exploited for application in the area of solvent removal from water.

With respect to metal ion removal from aqueous systems, mention is only made of one study related to the porphyrincontaining materials prepared by Shi et al. ${ }^{18,22,50,52}$ Here iron and manganese binding capabilities were demonstrated but not explored in regards to species removal. Binding studies focused on either blocking or increasing pore sizes and surface areas rather than the removal of metal ions from aqueous systems, leaving this aspect wide open for further exploration.

4.3.3. Sensing. Predominantly, sensing studies focus on metal ion sensing in both organic and aqueous systems. Liao et $a l .{ }^{62}$ utilised pPIs derived from $\mathbf{B 1}$ and $\mathbf{L 5}$ that demonstrate strong yellow-green fluorescence (here a reduction in $\pi-\pi$ stacking of the synthesised pPIs hinders self-quenching and hence gives amplified fluorescence) in simple quenching studies. Fluorescence quenching was tested for a range of ions, with only $\mathrm{Fe}^{3+}$ eliciting significant quenching (greater than 50\%). Wang et $a .^{30}$ also employed a melamine-B1 based pPI (with both $\mathbf{L 3}$ and $\mathbf{L 4}$ ) that fluoresced in DMF (as well as other solvents) to detect $\mathrm{Fe}^{3+}$ via fluorescence quenching. Here the quenching was attributed to effective energy transfer from the emission level of pPI to the unoccupied d-orbitals of $\mathrm{Fe}^{3+}$. Other metals also showed fluorescent enhancement and linear shifts in excitation wavelengths but were not investigated in any further detail in these studies.

Further sensing of heavy metal ions by fluorescence quenching was demonstrated by Xiao et al., ${ }^{56}$ specifically sensing $\mathrm{Cr}^{3+}$ ions. It was theorised that the strong binding of $\mathrm{Cr}^{3+}$ ions to the triazine nitrogen atoms (B1), as well as oxygen atoms from the imide bonds within the pPI framework, led to a reduction in antenna efficiency and hence an increase in quenching of the luminescence.

Beyond heavy metal sensing, Zhang et al. ${ }^{74}$ demonstrated a porphyrin (C7) and perylenetetracarboxylic dianhydride (L5) derived pPI for 2,4,6-trinitrophenol (TNP) detection, an explosive with higher efficacy than its counterpart 2,4,6-trinitrotoluene (TNT), via fluorescence dampening. Interestingly, the pPI shows selectivity for TNP detection over other nitroaromatics, which was tentatively attributed to a reduction in $\pi-\pi$ stacking (although not explored in any detail).

4.3.4. Functionalised coatings. Where crosslinked polyimides can be manipulated into processable materials (either by blending or direct casting) a few examples were found for coating applications. Li et al. $^{49}$ synthesised fluorinated crosslinked polyimides for UV screening applications. They showed how films containing the pPI could reduce the photocatalytic degradation of methylene blue (18\% degradation over $1 \mathrm{~h}$ compared to above $90 \%$ for the control films with no pPI incorporated), whilst still retaining transparency $(80 \%$ at $800 \mathrm{~nm})$.

Further applications of pPIs as coatings can be found in the work by Qiao et al. ${ }^{79}$ who prepared fluorinated pPIs as waterrepellent coatings. They found that increasing the content of the $\mathrm{CF}_{3}$-functionalised monomers of the pPI from 0 to $50 \mathrm{wt} \%$ increased the water contact angle from $87.7^{\circ}$ to $112.1^{\circ}$, allowing optimisation of water repulsion.

Finally, it is noted that the majority of publications do not investigate the chemical stability of pPIs in great detail. One example of stability investigations can be found in van der Jagt et al. ${ }^{75}$ submerging pPIs PIC and PID (see Table 1 ) for 14 days in organic (1 $\mathrm{M} \mathrm{NaClO}_{4}$ in ethylene carbonate (EC)/dimethylcarbonate (DMC)) and aqueous $\left(1 \mathrm{M} \mathrm{Na}_{2} \mathrm{SO}_{4}\right.$ in neutral water) electrolytes, both of which are representative electrolytes used in energy storage application. Both crystalline pPIs (PIC and PID) were found to have identical powder XRD spectra before and after, used as a proof of stability of these highly crosslinked materials in these application-relevant environments.

\section{Future outlook}

One common theme throughout the studies cited in this review was centred around the ability and opportunities available to control the properties and the function of the prepared pPIs. We have endeavoured to highlight aspects of deliberate design where encountered, and attempted to show the influence of careful choice of starting materials and their functionality, and synthesis conditions on the chosen areas of applications. There are however a number of challenges that the broader field of porous functional materials, and certainly also pPIs, face that are connected to fine control of properties and function.

Although pPIs can be synthesised solvent free to avoid issues with insolubility and the incompatibility of the growing and crosslinked polymer chains with reaction solvents, Chen et al. ${ }^{120,121}$ have recently explored tuning Hansen solubility parameters (HSPs) in the preparation of CMPs through the addition of simple inorganic salts to reaction mixture. They showed that this approach, the so-called Bristol-Xi'an Jiaotong (BXJ) approach, provides a novel route to accurately match the HSPs of the growing polymer construct with that of the reaction solvent, thus exerting fine control over the properties and functionality (as expressed through increased $\mathrm{CO}_{2}$ uptake) in the obtained porous materials. Significant opportunities therefore exist, especially when keeping Tables 1 and 3 in mind in terms of scope of materials, to apply the BXJ approach for the production optimized and fully tuned functional pPI networks.

In terms of application areas as potential future growth areas, especially those with an environmental application is of global interest. Given the current world shortages in water (for safe human consumption, but also for wider agricultural use), the use of pPIs as water harvesting motifs presents a significant opportunity. Although pPIs synthesised by $\mathrm{Wu}$ et al. ${ }^{82}$ demonstrate large water uptake (over $300 \mathrm{wt} \%$ ), and while many other systems were reported as having the capability (Table 4), water harvesting remains largely unexplored in the majority of papers where gas absorption is presented as an application (Table 3). It is expected that significant increases 
in performance would be possible with focused efforts in this area of importance, thus leading to significant global socioeconomic impact on local communities where water is a precious commodity.

To the best of our knowledge biocompatibility of pPIs has not been reported in the literature. This omission is especially worthy of attention when one considers the potential of these networks as controlled drug delivery or drug removal motifs (as discussed in sections 5.1 and 5.2), as potential scaffolds for cell culture and growth (for biocompatible implants), as well as the possibility for in vitro drug detection, section 5.3.

Finally, the excellent surface areas reported, high wt $\%$ of $\mathrm{CO}_{2}$ capture, and tuneable conductivity of the reported pPIs make them excellent candidates for electro- and photo-catalytic $\mathrm{CO}_{2}$ capture and conversion. Other POFs have been utilised successfully in this field. ${ }^{101,122-127}$ Recent advances show that the photocatalytic $\mathrm{CO}_{2}$ conversion can be carried out in porous polymers even in the absence of metal atoms; ${ }^{112,128,129}$ yet this area has not been explored at all with pPIs to date, and presents a significant opportunity to address global challenges presented by continued and growing human activity and influence on the environment. In particular, recent focus has been placed on the direct conversion of $\mathrm{CO}_{2}$ to useful chemicals (rather than storage). ${ }^{130,131}$ For instance, robust and moistureinsensitive pPIs incorporating functional groups such as hydrogen-bond donors, ${ }^{132,133}$ nucleophilic species such as pyridines, ${ }^{134,135}$ or Lewis acidic metal centres ${ }^{136,137}$ could serve as components of catalytic systems for the direct conversion of $\mathrm{CO}_{2}$ and epoxides to cyclic carbonates. Further opportunities in energy conversion and storage (as touched on in section 4.2 focusing on photocatalysis) are also available for further significant effort and exploitation.

In conclusion, we believe that pPIs, as a class of materials, present a range of exciting possibilities to contribute to solutions for a range of global challenges. The hope is that this review will provide readers and researchers with a range of opportunities for future exploration, thus contributing to solutions for the significant problems that society currently faces.

\section{Conflicts of interest}

There are no conflicts to declare.

\section{Acknowledgements}

B.B.N acknowledges support from the National Overseas Scholarship for ST Students, Government of India. N. Y. and V. D'E. acknowledge support from Vidyasirimedhi Institute of Science and Technology (VISTEC), Thailand. B. C. B. and C. F. J. F. acknowledge the EPSRC (EP/T020792/1) for support. The authors thank Marcos Villeda Hernandez for graphic design and images.

\section{Notes and references}

1 M. T. Borget and R. R. Renshaw, J. Am. Chem. Soc., 1908, 30, 1135-1144.

2 C. E. Sroog, Prog. Polym. Sci., 1991, 16, 561-694.

3 W. M. Edwards and I. M. Robinson, United States Patent Office, 14 June 1955, 2710853.

4 L. T. C. Lee, E. M. Pearce and S. S. Hirsch, J. Polym. Sci., 1971, 9, 3169-3174.

5 Y. Zhuang, J. G. Seong and Y. M. Lee, Prog. Polym. Sci., 2019, 92, 35-88.

6 D.-J. Liaw, K.-L. Wang, Y.-C. Huang, K.-R. Lee, J.-Y. Lai and C.-S. Ha, Prog. Polym. Sci., 2012, 37, 907-974.

7 M. Hasegawa and K. Horie, Prog. Polym. Sci., 2001, 26, 259-335.

8 M. Ding, Prog. Polym. Sci., 2007, 32, 623-668.

9 Q. Fang, Z. Zhuang, S. Gu, R. B. Kaspar, J. Zheng, J. Wang, S. Qiu and Y. Yan, Nat. Commun., 2014, 5, 4503.

10 M.-C. Fu, T. Higashihara and M. Ueda, Polym. J., 2017, 50, $57-76$.

11 M. Hasegawa, Polymers, 2017, 9, 520.

12 L. Y. Jiang, Y. Wang, T.-S. Chung, X. Y. Qiao and J.-Y. Lai, Prog. Polym. Sci., 2009, 34, 1135-1160.

13 K. Vanherck, G. Koeckelberghs and I. F. J. Vankelecom, Prog. Polym. Sci., 2013, 38, 874-896.

14 E. P. Favvas, F. K. Katsaros, S. K. Papageorgiou, A. A. Sapalidis and A. C. Mitropoulos, React. Funct. Polym., 2017, 120, 104-130.

15 Y. Zhang, Z. Huang, B. Ruan, X. Zhang, T. Jiang, N. Ma and F. C. Tsai, Macromol. Rapid Commun., 2020, 41, 2000402.

16 N. Song, T. Ma, T. Wang, K. Shi, Y. Tian, H. Yao, Y. Zhang and S. Guan, Microporous Mesoporous Mater., 2020, 293, 109809.

17 M. R. Liebl and J. Senker, Chem. Mater., 2013, 25, 970980.

18 K. Shi, N. Song, Y. Zou, S. Zhu, H. Tan, Y. Tian, B. Zhang, H. Yao and S. Guan, Polymer, 2019, 169, 160-166.

19 E. Rangel Rangel, E. M. Maya, F. Sánchez, J. de Abajo and J. G. de la Campa, J. Membr. Sci., 2013, 447, 403-412.

20 J. Li, Y. Ding, N. Yu, Q. Gao, X. Fan, X. Wei, G. Zhang, Z. Ma and X. He, Carbon, 2020, 158, 45-54.

21 A. M. Shultz, O. K. Farha, J. T. Hupp and S. T. Nguyen, Chem. Sci., 2011, 2, 686-689.

22 K. Shi, H. Yao, S. Zhang, Y. Wei, W. Xu, N. Song, S. Zhu, Y. Tian, Y. Zou and S. Guan, Ind. Eng. Chem. Res., 2019, 58, 14146-14153.

23 A. Roy, S. Mondal, A. Halder, A. Banerjee, D. Ghoshal, A. Paul and S. Malik, Eur. Polym. J., 2017, 93, 448457.

24 Y. F. Lu, Y. M. Wang, X. D. Chen, M. H. Miao and D. H. Zhang, eXPRESS Polym. Lett., 2020, 14, 192-204.

25 T. Zhu, Q. Yu, L. Ding, T. Di, T. Zhao, T. Li and L. Li, Green Chem., 2019, 21, 2326-2333.

26 S. Chu, Y. Wang, C. Wang, J. Yang and Z. Zou, Int. J. Hydrogen Energy, 2013, 38, 10768-10772. 
27 S. Chu, Y. Wang, Y. Guo, P. Zhou, H. Yu, L. Luo, F. Kong and Z. Zou, J. Mater. Chem., 2012, 22, 15519-15521.

28 Y. Wang, Q. Gao, Q. You, G. Liao, H. Xia and D. Wang, React. Funct. Polym., 2016, 103, 9-16.

29 C. Simón-Herrero, X.-Y. Chen, M. L. Ortiz, A. Romero, J. L. Valverde and L. Sánchez-Silva, J. Mater. Res. Technol., 2019, 8, 2638-2648.

30 T. Wang, R. Xue, H. Chen, P. Shi, X. Lei, Y. Wei, H. Guo and W. Yang, New J. Chem., 2017, 41, 14272-14278.

31 M. Hasegawa, R. Tokunaga, K. Hashimoto and J. Ishii, React. Funct. Polym., 2019, 139, 181-188.

32 J. G. Kim, J. Lee, J. Lee, S. I. Jo and J. Y. Chang, Macromol. Res., 2017, 25, 629-634.

33 T. Wang, H. Yao, N. Song, Y. Yang, K. Shi and S. Guan, Ind. Eng. Chem. Res., 2020, 59, 2953-2959.

34 G. Li and Z. Wang, J. Phys. Chem. C, 2013, 117, $24428-24437$.

35 J. Wu, L. Xia, S. Zhang and X. Liu, Mater. Today Commun., 2020, 24, 101030.

36 Z. Li, J. Zhou, R. Xu, S. Liu, Y. Wang, P. Li, W. Wu and M. Wu, Chem. Eng. J., 2016, 287, 516-522.

37 H. Yao, N. Zhang, K. Shen, N. Song, K. Shi, S. Zhu, Y. Zhang and S. Guan, Polymer, 2017, 115, 176-183.

38 K. V. Rao, R. Haldar, C. Kulkarni, T. K. Maji and S. J. George, Chem. Mater., 2012, 24, 969-971.

39 K. V. Rao, R. Haldar, T. K. Maji and S. J. George, Polymer, 2014, 55, 1452-1458.

40 H. Yao, N. Zhang, N. Song, K. Shen, P. Huo, S. Zhu, Y. Zhang and S. Guan, Polym. Chem., 2017, 8, 1298-1305.

41 C. Zhang, T.-L. Zhai, J.-J. Wang, Z. Wang, J.-M. Liu, B. Tan, X.-L. Yang and H.-B. Xu, Polymer, 2014, 55, 3642-3647.

42 M. E. Dose, M. Chwatko, I. Hubacek, N. A. Lynd, D. R. Paul and B. D. Freeman, Polymer, 2019, 161, 16-26.

43 H. Gao, B. Tian, H. Yang, A. R. Neale, M. A. Little, R. S. Sprick, L. J. Hardwick and A. I. Cooper, ChemSusChem, 2020, 13, 5571-5579.

44 Q. Fang, J. Wang, S. Gu, R. B. Kaspar, Z. Zhuang, J. Zheng, H. Guo, S. Qiu and Y. Yan, J. Am. Chem. Soc., 2015, 137, 8352-8355.

45 Y. Luo, B. Li, L. Liang and B. Tan, Chem. Commun., 2011, 47, 7704-7706.

46 I. Hossain, A. Z. Al Munsur, O. Choi and T.-H. Kim, Sep. Purif. Technol., 2019, 224, 180-188.

47 J. Lee and J. Y. Chang, Chem. Commun., 2016, 52, 1041910422.

48 G. Li, B. Zhang, J. Yan and Z. Wang, J. Mater. Chem. A, 2016, 4, 11453-11461.

49 Q. Li, R. Chen, Y. Guo, F. Lei, Z. Xu, H. Zhao and G. Liao, Polymers, 2020, 12, 88.

50 K. Shi, H. Yao, Y. Zou, Y. Wei, N. Song, S. Zhang, Y. Tian, S. Zhu, B. Zhang and S. Guan, Microporous Mesoporous Mater., 2019, 287, 246-253.

51 D. H. Wang and L.-S. Tan, ACS Macro Lett., 2019, 8, 546552.

52 K. Shi, H. Yao, Y. Zou, Y. Wei, S. Zhang, Y. Song, N. Song, T. Wang, Y. Tian, S. Zhu and S. Guan, Microporous Mesoporous Mater., 2020, 292, 109739.
53 L. Yu, L. Wang, L. Yu, D. Mu, L. Wang and J. Xi, J. Membr. Sci., 2019, 572, 119-127.

54 E. Rangel Rangel, E. M. Maya, F. Sánchez, J. G. de la Campa and M. Iglesias, Green Chem., 2015, 17, 466-473.

55 T. Wu, J. Dong, K. De France, P. Zhang, X. Zhao and Q. Zhang, Chem. Eng. J., 2020, 395.

56 J.-D. Xiao, L.-G. Qiu, Y.-P. Yuan, X. Jiang, A.-J. Xie and Y.-H. Shen, Inorg. Chem. Commun., 2013, 29, 128-130.

57 C. Shen, Y. Bao and Z. Wang, Chem. Commun., 2013, 49, 3321.

58 H. Zhou, H. Lei, J. Wang, S. Qi, G. Tian and D. Wu, Polymer, 2019, 162, 116-120.

59 C. Shen and Z. Wang, J. Phys. Chem. C, 2014, 118, 1758517593.

60 N. Song, T. Wang, H. Yao, T. Ma, K. Shi, Y. Tian, Y. Zou, S. Zhu, Y. Zhang and S. Guan, Polym. Chem., 2019, 10, 4611-4620.

61 N. Song, H. Yao, T. Ma, T. Wang, K. Shi, Y. Tian, Y. Zou, S. Zhu, Y. Zhang and S. Guan, Chem. Eng. J., 2019, 368, 618-626.

62 Y. Liao, J. Weber and C. F. J. Faul, Macromolecules, 2015, 48, 2064-2073.

63 J. Maschita, T. Banerjee, G. Savasci, F. Haase, C. Ochsenfeld and B. V. Lotsch, Angew. Chem., 2020, 59, 15750-15758.

64 Y. Tian, K. Shi, H. Yao, T. Wang, H. Liu, Y. Song, Y. Zhang and S. Guan, J. Phys. Chem. C, 2020, 124, 2872-2878.

65 Z. Wang, B. Zhang, H. Yu, L. Sun, C. Jiao and W. Liu, Chem. Commun., 2010, 46, 7730.

66 Z. Wu, B. Han, C. Zhang, D. Zhu and Z. Yang, Polymer, 2019, 179, 121605.

67 J. Yan, B. Zhang and Z. Wang, ACS Appl. Mater. Interfaces, 2018, 10, 26618-26627.

68 N. Song, T. Ma, T. Wang, Z. Li, H. Yao and S. Guan, J. Colloid Interface Sci., 2020, 573, 328-335.

69 J. Yan, B. Zhang, L. Guo and Z. Wang, J. Phys. Chem. C, 2019, 123, 575-583.

70 D. Tian, H.-Z. Zhang, D.-S. Zhang, Z. Chang, J. Han, X.-P. Gao and X.-H. Bu, RSC Adv., 2014, 4, 7506-7510.

71 L. Jiang, Y. Tian, T. Sun, Y. Zhu, H. Ren, X. Zou, Y. Ma, K. R. Meihaus, J. R. Long and G. Zhu, J. Am. Chem. Soc., 2018, 140, 15724-15730.

72 W. Zhu, X. Wang, T. Li, R. Shen, S.-J. Hao, Y. Li, Q. Wang, Z. Li and Z.-G. Gu, Polym. Chem., 2018, 9, 1430-1438.

73 J. Lv, Y. X. Tan, J. Xie, R. Yang, M. Yu, S. Sun, M. D. Li, D. Yuan and Y. Wang, Angew. Chem., Int. Ed., 2018, 57, 12716-12720.

74 C. Zhang, S. Zhang, Y. Yan, F. Xia, A. Huang and Y. Xian, ACS Appl. Mater. Interfaces, 2017, 9, 13415-13421.

75 R. van der Jagt, A. Vasileiadis, H. Veldhuizen, P. Shao, X. Feng, S. Ganapathy, N. C. Habisreutinger, M. A. van der Veen, C. Wang, M. Wagemaker, S. van der Zwaag and A. Nagai, Chem. Mater., 2021, 33, 818-833.

76 S. Royuela, E. Martinez-Perinan, M. P. Arrieta, J. I. Martinez, M. M. Ramos, F. Zamora, E. Lorenzo and J. L. Segura, Chem. Commun., 2020, 56, 1267-1270. 
77 G. Zhao, H. Li, Z. Gao, L. Xu, Z. Mei, S. Cai, T. Liu, X. Yang, H. Guo and X. Sun, Adv. Funct. Mater., 2021, 31, 2101019.

78 X. Zhang, X. Cui, C.-H. Lu, H. Li, Q. Zhang, C. He and Y. Yang, Chem. Eng. J., 2020, 401, 126031.

79 S. Qiao, S. Kang, Z. Hu, J. Yu, Y. Wang and J. Zhu, J. Porous Mater., 2019, 27, 237-247.

80 Q. Fang, J. Wang, S. Gu, R. B. Kaspar, Z. Zhuang, J. Zheng, H. Guo, S. Qiu and Y. Yan, J. Am. Chem. Soc., 2015, 137, 8352-8355.

81 Z. Wang, B. Zhang, H. Yu, L. Sun, C. Jiao and W. Liu, Chem. Commun., 2010, 46, 7730-7732.

82 Z. Wu, B. Han, C. Zhang, D. Zhu and Z. Yang, Polymer, 2019, 179, 121605.

83 J. Lee and J. Y. Chang, Chem. Commun., 2016, 52, 1041910422.

84 S. Liu, W. Chen and X. Zhou, J. Porous Mater., 2021, 28, 1155-1165.

85 C. Shen, Y. Bao and Z. Wang, Chem. Commun., 2013, 49, 3321-3323.

86 G. Li and Z. Wang, Macromolecules, 2013, 46, 3058-3066.

87 J.-S. M. Lee and A. I. Cooper, Chem. Rev., 2020, 120, 21712214.

88 F. Wang, X. Wu, X. Yuan, Z. Liu, Y. Zhang, L. Fu, Y. Zhu, Q. Zhou, Y. Wu and W. Huang, Chem. Soc. Rev., 2017, 46, 6816-6854.

89 R. Heimbockel, F. Hoffmann and M. Froba, Phys. Chem. Chem. Phys., 2019, 21, 3122-3133.

90 J.-S. M. Lee, T.-H. Wu, B. M. Alston, M. E. Briggs, T. Hasell, C.-C. Hu and A. I. Cooper, J. Mater. Chem. A, 2016, 4, 7665-7673.

91 Y. Wang, Y. Song and Y. Xia, Chem. Soc. Rev., 2016, 45, 5925-5950.

92 Y. Jiang and J. Liu, Energy Environ. Mater., 2019, 2, 30-37.

93 Y. Xu, S. Jin, H. Xu, A. Nagai and D. Jiang, Chem. Soc. Rev., 2013, 42, 8012-8031.

94 H. Wu, Q. Meng, Q. Yang, M. Zhang, K. Lu and Z. Wei, Adv. Mater., 2015, 27, 6504-6510.

95 Z. Song, H. Zhan and Y. Zhou, Angew. Chem., Int. Ed., 2010, 49, 8444-8448.

96 X. Han, C. Chang, L. Yuan, T. Sun and J. Sun, Adv. Mater., 2007, 19, 1616-1621.

97 W. Luo, C. Bommier, Z. Jian, X. Li, R. Carter, S. Vail, Y. Lu, J. J. Lee and X. Ji, ACS Appl. Mater. Interfaces, 2015, 7, 2626-2631.

98 J. Guo, C. Y. Lin, Z. Xia and Z. Xiang, Angew. Chem., Int. Ed., 2018, 57, 12567-12572.

99 Q. Xu, Y. Tang, X. Zhang, Y. Oshima, Q. Chen and D. Jiang, Adv. Mater., 2018, 30, 1706330.

100 D. Wu, Q. Xu, J. Qian, X. Li and Y. Sun, Chemistry, 2019, 25, 3105-3111.

101 G. Singh, J. Lee, A. Karakoti, R. Bahadur, J. Yi, D. Zhao, K. AlBahily and A. Vinu, Chem. Soc. Rev., 2020, 49, 43604404.

102 A. Nuhnen and C. Janiak, Dalton Trans., 2020, 49, 1029510307.
103 P. Atkins, J. de Paula and J. Keeler, Physical Chemistry, Oxford University Press, 2018.

104 P. P. Edwards, V. L. Kuznetsov, W. I. F. David and N. P. Brandon, Energy Policy, 2008, 36, 4356-4362.

105 S. Sharma and S. K. Ghoshal, Renewable Sustainable Energy Rev., 2015, 43, 1151-1158.

106 I. P. Jain, Int. J. Hydrogen Energy, 2009, 34, 7368-7378.

107 M. P. Suh, H. J. Park, T. K. Prasad and D. W. Lim, Chem. Rev., 2012, 112, 782-835.

108 S. S. Han, H. Furukawa, O. M. Yaghi and W. A. Goddard, J. Am. Chem. Soc., 2007, 130, 11580-11581.

109 H. Furukawa, N. Ko, Y. B. Go, N. Aratani, S. B. Choi, E. Choi, A. Ö. Yazaydin, R. Q. Snurr, M. O’Keeffe, J. Kim and O. M. Yaghi, Science, 2010, 329, 424-428.

110 J. Yan, B. Zhang and Z. Wang, ACS Appl. Mater. Interfaces, 2018, 10, 26618-26627.

111 P. Kaur, J. T. Hupp and S. T. Nguyen, ACS Catal., 2011, 1, 819-835.

112 T.-X. Wang, H.-P. Liang, D. A. Anito, X. Ding and B.-H. Han, J. Mater. Chem. A, 2020, 8, 7003-7034.

113 Y. Chen, R. Luo, Q. Xu, W. Zhang, X. Zhou and H. Ji, ChemCatChem, 2017, 9, 767-773.

114 R. R. Shaikh, S. Pornpraprom and V. D'Elia, ACS Catal., 2018, 8, 419-450.

115 F. Della Monica and A. W. Kleij, Catal. Sci. Technol., 2020, 10, 3483-3501.

116 V. Aomchad, À. Cristòfol, F. Della Monica, B. Limburg, V. D'Elia and A. W. Kleij, Green Chem., 2021, 23, 10771113.

117 Z. Wei and C. F. J. Faul, Macromol. Rapid Commun., 2008, 29, 280-292.

118 F. Qu, G. Zhu, H. Lin, W. Zhang, J. Sun, S. Li and S. Qiu, J. Solid State Chem., 2006, 179, 2027-2035.

119 P. Horcajada, C. Serre, M. Vallet-Regí, M. Sebban, F. Taulelle and G. Férey, Angew. Chem., 2006, 118, 61206124.

120 J. Chen, W. Yan, E. J. Townsend, J. Feng, L. Pan, V. Del Angel Hernandez and C. F. J. Faul, Angew. Chem., Int. Ed., 2019, 58, 11715-11719.

121 J. Chen, T. Qiu, W. Yan and C. F. J. Faul, J. Mater. Chem. A, 2020, 8, 22657-22665.

122 P. Bhanja, A. Modak and A. Bhaumik, ChemCatChem, 2018, 11, 244-257.

123 H. Liu, J. Chu, Z. Yin, X. Cai, L. Zhuang and H. Deng, Chem, 2018, 4, 1696-1709.

124 M. Lu, M. Zhang, C. G. Liu, J. Liu, L. J. Shang, M. Wang, J. N. Chang, S. L. Li and Y. Q. Lan, Angew. Chem., 2021, 60, 4864-4871.

125 L. Majidi, A. Ahmadiparidari, N. Shan, S. N. Misal, K. Kumar, Z. Huang, S. Rastegar, Z. Hemmat, X. Zou, P. Zapol, J. Cabana, L. A. Curtiss and A. Salehi-Khojin, Adv. Mater., 2021, 33, 2004393.

126 R. Sharma, A. Bansal, C. N. Ramachandran and P. Mohanty, Chem. Commun., 2019, 55, 11607-11610.

127 S. Yang, W. Hu, X. Zhang, P. He, B. Pattengale, C. Liu, M. Cendejas, I. Hermans, X. Zhang, J. Zhang and 
J. Huang, J. Am. Chem. Soc., 2018, 140, 1461414618.

128 Y. Fu, X. Zhu, L. Huang, X. Zhang, F. Zhang and W. Zhu, Appl. Catal., B, 2018, 239, 46-51.

129 K. Lei, D. Wang, L. Ye, M. Kou, Y. Deng, Z. Ma, L. Wang and Y. Kong, ChemSusChem, 2020, 13, 1725-1729.

130 J. W. Maina, J. M. Pringle, J. M. Razal, S. Nunes, L. Vega, F. Gallucci and L. F. Dumee, ChemSusChem, 2021, 14, 1805-1820.

131 O. Sodpiban, C. Phungpanya, S. Del Gobbo, S. Arayachukiat, T. Piromchart and V. D'Elia, Chem. Eng. J., 2021, 422, 129930.

132 P. Yingcharoen, W. Natongchai, A. Poater and V. D'Elia, Catal. Sci. Technol., 2020, 10, 5544-5558.
133 C. J. Whiteoak, A. Nova, F. Maseras and A. W. Kleij, ChemSusChem, 2012, 5, 2032-2038.

134 S. Subramanian, J. Park, J. Byun, Y. Jung and C. T. Yavuz, ACS Appl. Mater. Interfaces, 2018, 10, 9478-9484.

135 W. Natongchai, J. A. Luque-Urrutia, C. Phungpanya, M. Solà, V. D'Elia, A. Poater and H. Zipse, Org. Chem. Front., 2021, 8, 613-627.

136 J. Meléndez, M. North and R. Pasquale, Eur. J. Inorg. Chem., 2007, 2007, 3323-3326.

137 O. Sodpiban, S. Del Gobbo, S. Barman, V. Aomchad, P. Kidkhunthod, S. Ould-Chikh, A. Poater, V. D'Elia and J.-M. Basset, Catal. Sci. Technol., 2019, 9, 61526165. 